This item was submitted to Loughborough's Research Repository by the author.

Items in Figshare are protected by copyright, with all rights reserved, unless otherwise indicated.

\title{
A comparative evaluation of the disulfur dinitride process for the visualisation of fingermarks on metal surfaces
}

PLEASE CITE THE PUBLISHED VERSION

https://doi.org/10.1016/j.scijus.2019.06.011

\section{PUBLISHER}

Elsevier BV on behalf of The Chartered Society of Forensic Science (c) Crown Copyright

\section{VERSION}

AM (Accepted Manuscript)

\section{PUBLISHER STATEMENT}

This paper was accepted for publication in the journal Science \& Justice and the definitive published version is available at https://doi.org/10.1016/j.scijus.2019.06.011.

\section{LICENCE}

CC BY-NC-ND 4.0

\section{REPOSITORY RECORD}

Bleay, Stephen M., Paul Kelly, Roberto S.P. King, and S.G. Thorngate. 2019. "A Comparative Evaluation of the Disulfur Dinitride Process for the Visualisation of Fingermarks on Metal Surfaces". figshare. https://hdl.handle.net/2134/38305. 


\title{
A comparative evaluation of the disulfur dinitride process for the visualisation of fingermarks on metal surfaces
}

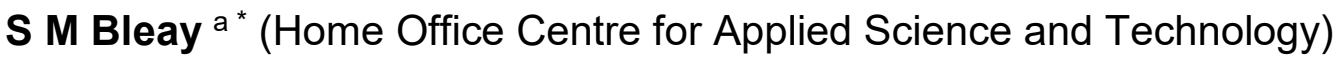

P F Kelly ${ }^{\mathrm{b}}$ (Loughborough University)

R S P King ${ }^{~}$ (Foster + Freeman)

S G Thorngate ${ }^{d}$ (Defence Science \& Technology Laboratory)

${ }^{a}$ Home Office Centre for Applied Science and Technology, Woodcock Hill, Sandridge, Hertfordshire AL4 9HQ

${ }^{\mathrm{b}}$ Department of Chemistry, Loughborough University, Loughborough, Leicestershire LE11 3TU

${ }^{c}$ Foster + Freeman Ltd, Vale Park, Evesham, Worcestershire, WR11 1TD

dDstl, Porton Down, Salisbury, Wiltshire, SP4 OJQ

*Corresponding author (bleays@Isbu.ac.uk)

\begin{abstract}
The disulfur dinitride process for fingermark visualisation was first reported a decade ago, with promising results obtained for a range of materials including metals.

However, the friction sensitive nature of the material and difficulty of synthesis made routine use difficult. Many of these issues have since been addressed, making equipment and chemicals available to build an understanding of how the effectiveness of disulfur dinitride compares to other fingermark visualisation processes currently used on metal surfaces. This enables more informed advice to be given on selection of processes for treatment of metal items, an area of operational interest that encompasses weapons used in violent crime and the increasing incidence in metal theft. This paper reports a comparative study into the effectiveness of disulfur dinitride, cyanoacrylate fuming, vacuum metal deposition, gun blueing and wet powder suspensions on brass, bronze, copper and stainless steel. Experiments were conducted with the surfaces exposed to a range of environments including long term ageing, water/detergent washing, acetone washing and high temperature exposure. The results indicate that disulfur dinitride is an effective process for fingermark visualisation on metal surfaces, including those exposed to adverse environments, and may offer potential improvements over existing processes for those surfaces. Further work, including pseudo-operational trials, is recommended.
\end{abstract}


Keywords: Fingermarks, metals, visualisation, disulfur dinitride, environmental exposure

\section{Introduction}

Chemical techniques for the visualisation of latent fingermarks have been reported from the mid-1800s [1]. This even pre-dates the introduction of the comparison of fingerprints with crime scene marks as a means of identifying the perpetrators of crime, and the development of techniques to visualise fingermarks on the wide range of surfaces that may be encountered has been a rich area of research from the 1900 s onwards $[2,3]$.

The modern forensic practitioner potentially has access to a comprehensive suite of visualisation and imaging processes for the recovery of fingermarks [4], and the selection of the most appropriate processes may be tailored according to knowledge of the type of surface that is present and the environment it has been exposed to. However, the surfaces that may be encountered during criminal investigations may change over time (for example recent increases in the recycled content of plastic bags [5] or changes from paper to polymer banknotes [6, 7, 8], and there remain surfaces for which fingermark recovery has always been problematic (for example leather [9], fabrics [10] and clingfilm [11]). As a consequence, there is an ongoing requirement to evaluate techniques that could increase the fingermark yield from 'problem' surfaces.

One type of surface for which fingermark recovery appears lower than may be expected, is metals. Although metals can be regarded as a 'non-porous' surface, they differ from other non-porous surfaces in that most metals and alloys are not chemically inert and chemical interactions can occur between the metal surface and the fingermark deposits $[12,13,14]$. These interactions may prove detrimental or beneficial to subsequent fingermark recovery. Although many of the processes recommended [4] for non-porous surfaces are reasonably effective in visualising fingermarks on metals, their effectiveness is often less than their equivalent performance on other non-porous surfaces such as glass, ceramic and polymers.

Metals are a surface of significant operational interest. In recent years there has been a rise in the commercial value of metals and a corresponding increase in the crime of metal theft [15]. There has also been a much-publicised increase in violent crimes [16] with a $42 \%$ year on year increase in gun crime leading to 2,544 offences recorded in 2016/17, and a $24 \%$ increase in knife crime over the same period with over 4,000 offences resulting in injury reported in the Metropolitan Police area alone. Metal surfaces associated with these crimes include brass (for fired and unfired cartridge casings) and stainless steel (for knife blades). Any increase in fingermark recovery from such items will contribute to the reduction in crimes of this type. 
Cartridge casings have been long recognised as a problematic substrate for fingermark recovery, and the reported success rates from fired cartridges worldwide are very low. A series of studies that attempt to address this issue have been reported from the 1970s onwards, with researchers exploring processes for selectively etching metals and electrodeposition from solution. Nitric acid was proposed as a fuming process for selective etching [17], and the potential of gun blueing as a selective electrodeposition process for steel and copper-based alloys was also recognised [18]. Other researchers have proposed similar etching and electrodeposition processes both for copper-based alloys and other metals such as aluminium, including potassium permanganate [19], acidified hydrogen peroxide [20], palladium deposition [21], aluminium black [22] and cold patination fluid [23].

Comparative studies have also been conducted by different research groups, looking at these processes singly and in sequence with other processes such as cyanoacrylate fuming $[24,25,26,27]$. In general, the results from these studies indicate that palladium deposition and gun blueing tend to give the best results, and the best sequences include these processes used in sequence after cyanoacrylate fuming. However, focused studies into the impact of the firing process into fingermark recovery [28] confirm that the high temperatures, abrasion and deposition of propellant residue all reduce the chances of recovering fingermarks, and this is in accord with the low operational recovery rates observed on fired ammunition.

It has been noted that on copper-based alloys, residual corrosion may be left on the surface by the interaction between the fingermark and the metal, and this 'signature' may be persistent even when marks are washed or rubbed away. The first technique to utilise this effect was the Scanning Kelvin Probe $[29,30]$ where a fine ( $\mu \mathrm{m}$ scale) vibrating gold probe is scanned across the metal surface and a map of Volta potential is recorded. The corrosion initiated by eccrine constituents, and the thin insulating layer of sebaceous constituents on the surface both produce different Volta potentials to the bare metal surface and enable fingermarks to be visualised.

The same effect was utilised by Bond [13,14,31], who employed heating to enhance the corrosion signature, followed by electrostatic powdering (charging the casing and applying a toner powder) to reveal fingermarks. Although this process was commercialised, it ultimately proved difficult to reproduce the laboratory results on commercial equipment. Bond also conducted studies into the corrosion mechanisms occurring between the fingermark and the metal surface [14] and proposed that the main reaction was the action of chlorides to produce metal hydroxides and hydrochloric acid, although a subsequent study by Wightman and O'Connor [12] indicated this may not be the case and that other mechanisms, such as reduction of oxides by organic species in the fingermark, may also be operating.

Another discovery that is thought to utilise this corrosion signature to visualise fingermarks on brass and copper-based alloys is disulfur dinitride $\left(\mathrm{S}_{2} \mathrm{~N}_{2}\right)[32,33,34]$. The traditional process begins by decomposing the material tetrasulfur tetranitride 
$\left(\mathrm{S}_{4} \mathrm{~N}_{4}\right)$, to the active and volatile $\mathrm{S}_{2} \mathrm{~N}_{2}$ compound, under vacuum, where it is selectively polymerised to $(\mathrm{SN})_{x}$ on the fingermark ridges, Figure 1.

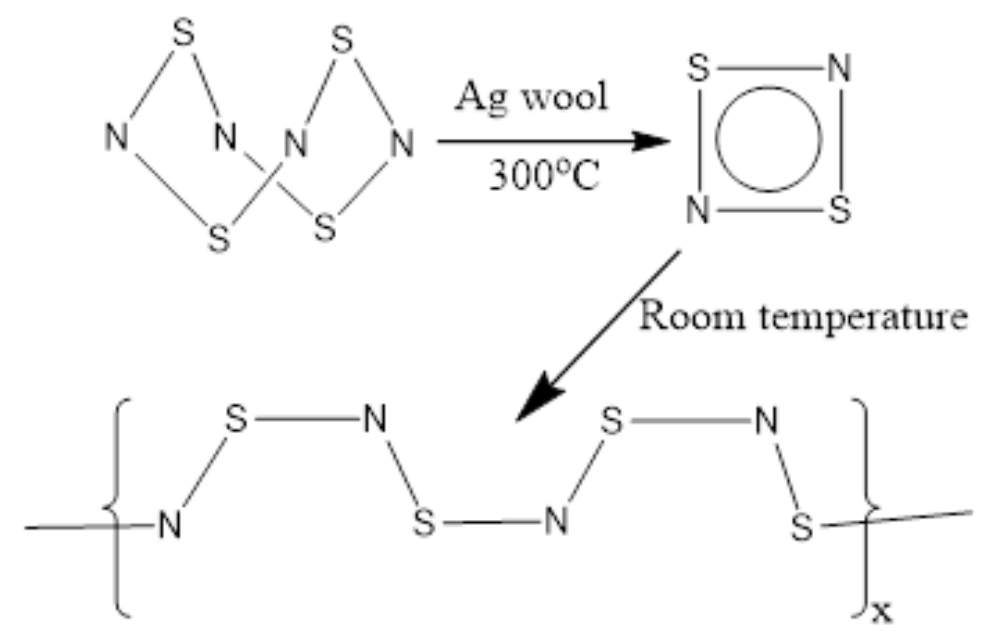

Figure 1. Reaction mechanism for the formation of $(S N)_{x}$ polymer from $S_{4} N_{4}$

Promising results have been obtained on brass using this process, and it was also observed that the process continued to visualise marks on surfaces that had been wiped clean [35].

In contrast to brass and copper-based alloys, there has been less focus on processes tailored towards the visualisation of fingermarks on stainless steel surfaces. This is partly because these surfaces are more chemically inert and existing processes such as cyanoacrylate fuming are reasonably effective. Increases in knife crime make this surface of more operational interest however, and there has been some work undertaken to develop electropolymerisation processes that are effective on this type of surface [36,37]. $\mathrm{S}_{2} \mathrm{~N}_{2}$ has also been observed to develop marks on stainless steel, although the development mode in this case is predominantly deposition of blue $(\mathrm{SN})_{\times}$on the background with the ridges remaining paler.

Since the first published papers into the $\mathrm{S}_{2} \mathrm{~N}_{2}$ process, research has predominantly focused on making the process more practical and safer to use by moving away from the utilisation of friction sensitive $\mathrm{S}_{4} \mathrm{~N}_{4}$ as well as in reducing processing times to those comparable with cyanoacrylate treatment. A practical solution utilising a safe to handle precursor that is rapidly decomposed to $\mathrm{S}_{2} \mathrm{~N}_{2}$ within the safe confines of the vacuum chamber has now been developed, and this forms the emphasis of the current work.

The study reported in this paper is designed to evaluate the effectiveness of $\mathrm{S}_{2} \mathrm{~N}_{2}$ on a range of operationally significant metal surfaces (including brass - used for cartridge casings, bronze and copper - associated with metal theft, and stainless steel - associated with knife crime). The performance of $\mathrm{S}_{2} \mathrm{~N}_{2}$ was compared to a 
range of existing processes that can be used on metal surfaces, which are listed below, together with the rationale for their selection:

- Superglue (cyanoacrylate) fuming - effective on non-porous surfaces, and also involves visualisation of fingermarks by polymerisation

- Vacuum metal deposition - a process that is known to be highly sensitive on non-porous surfaces, including those that have been wetted or exposed to high temperature [38]

- Gun blueing (used on copper-based samples only) - a selective deposition process optimised for copper-based alloys

- Powder suspensions (used on stainless steel only) - an effective process on non-porous surfaces, capable of developing marks on surfaces that have been wetted, and found to give good results on stainless steel but not on copper-based alloys [39]

The objective of the comparative study was to obtain an initial understanding of the performance of $\mathrm{S}_{2} \mathrm{~N}_{2}$ relative to existing processes to inform if and when it could be recommended for fingermark visualisation on metal surfaces. Generating such information is also a requirement for developing validation libraries for any novel process prior to its acceptance and implementation on operational casework.

\section{Methods and materials}

\section{Chemicals}

The chemicals used are summarised in Table 1.

\begin{tabular}{|l|l|}
\hline Process & Chemical \\
\hline Disulfur dinitride & $\begin{array}{l}\text { Sulfur-nitrogen-based reagent (Loughborough University, } \\
\text { UK) in the form of a free-flowing powder* }\end{array}$ \\
\hline Cyanoacrylate fuming & Cyanobloom (Foster + Freeman, Evesham, UK) \\
\hline Gun blueing & $\begin{array}{l}\text { 'Perma Blue® Liquid Gun Blue' (Birchwood-Casey, Eden } \\
\text { Prairie, USA) }\end{array}$ \\
\hline Powder suspensions & $\begin{array}{l}\text { 'Wet PowderTM Black' (Kjell Carlsson Innovation, } \\
\text { Sundbyberg, Sweden) }\end{array}$ \\
\hline $\begin{array}{l}\text { Vacuum metal } \\
\text { deposition }\end{array}$ & $\begin{array}{l}\text { Gold wire, Silver wire (Alfa Aesar, Heysham, UK) } \\
\text { Zinc foil (Sigma Aldrich, Gillingham, UK) }\end{array}$ \\
\hline${ }^{*}$ now manufactured as DEVELOP ${ }^{\mathrm{TM}}$ precursor (Foster + Freeman, Evesham UK)
\end{tabular}

Table 1. Chemicals and suppliers used during the study.

\section{Surfaces}

The following metal surfaces were used: 
- Bronze (approx. $88 \%$ copper and $12 \%$ tin)

- Brass (approx. $70 \%$ copper and $30 \%$ zinc)

- Copper

- Stainless steel (grade 304 - iron, with carbon $0.08 \%$ max, chromium $18-20 \%$, nickel $8-12 \%$, traces of manganese, phosphorus, sulphur, silicon, nitrogen)

All metals for this study were purchased from Alloy Sales Ltd (Hatfield, Hertfordshire, UK).

Panels were cut to give samples of $100 \times 150 \mathrm{~mm}$ for fingermark deposition.

Each surface was washed and scrubbed with a water-detergent mix, left to stand in Grade 2 reverse osmosis purified water before being removed and allowed to dry, then wiped down with ethanol and allowed to dry again before the deposition of fingermarks. This washing regime was devised to remove both water soluble and water insoluble contaminants from the surface of the metals, without leaving residues that could act as preferential corrosion sites.

\section{Equipment}

The equipment used for the $S_{2} N_{2}$ process in this study was a developmental system assembled from a combination of bespoke and commercial off-the-shelf components. This design incorporated observations on the desirable features of equipment used in previous research $[34,35]$ but on a larger scale. A schematic diagram of the assembly is shown in Figure 2 below.

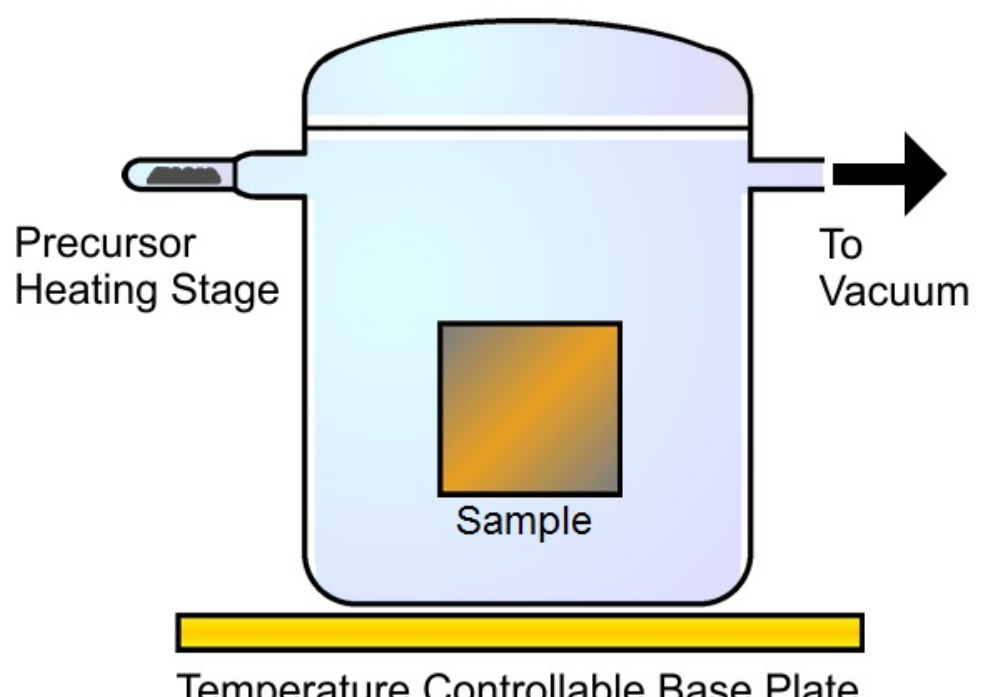

Figure 2. Schematic diagram of $S_{2} N_{2}$ processing equipment 
The glass vacuum vessel, lid, test tube and a three-way vacuum stopcock allowed the vessel to be evacuated and vented to atmosphere and this glassware was manufactured by Soham Scientific. The temperature control to the base plate was provided by two Otamat THP80 Peltier cooler/heater units, and an Edwards 3 vacuum pump was used to evacuate the vessel.

\section{Processing}

To conduct the $\mathrm{S}_{2} \mathrm{~N}_{2}$ process the test tube was loaded with precursor, with approximately $0.65 \mathrm{~g}$ being used for each run. Samples were placed within the vessel which was then sealed and evacuated. The base of the vessel was then chilled to below room temperature. The precursor was then heated until it had fully decomposed and orange $\mathrm{S}_{2} \mathrm{~N}_{2}$ crystals observed to have formed on the base of the vacuum vessel. The vessel was then sealed, the cooling units turned off, and the crystals on the base of the vessel allowed to sublime. When fingermarks were considered to have developed to a sufficient level the vessel was vented to atmosphere (typically after 45-90 minutes).

Cyanoacrylate fuming was conducted using an MVC5000 cabinet (Foster + Freeman, Evesham, UK) according to the process outlined in the Fingermark Visualisation Manual [4]. Approximately $2.5 \mathrm{~g}$ of Cyanobloom was used for each treatment. Developed fingermarks were dyed using Basic Yellow 40 (BY40) in ethanol [4].

Vacuum metal deposition was conducted using an E910 processing chamber (West Technology Forensics Ltd, Yate, UK). A maximum of two runs were conducted using the standard gold/zinc process [4], followed by a cycle of the silver process [4] if marks were not considered to be fully developed.

Gun blueing working solutions were prepared by diluting 3mL Perma Blue ${ }^{\circledR}$ with 97 $\mathrm{mL}$ of Grade 2 reverse osmosis purified water. Samples were immersed in the working solution until optimum contrast was observed between fingermark and background, then removed to a dish of purified water before rinsing under running tap water and drying at ambient temperature.

The powder suspensions container was shaken to achieve a paint-like consistency in the suspension mixture. The sample was first wetted by running under tap water then powder suspension was painted on with a soft, pre-wetted, animal hair fingerprint brush. Powder suspension was left in situ for approximately 15 seconds and then washed away under slowly running tap water. Samples were then allowed to dry in air.

A summary of the main features of the processes used is given in Table 2.

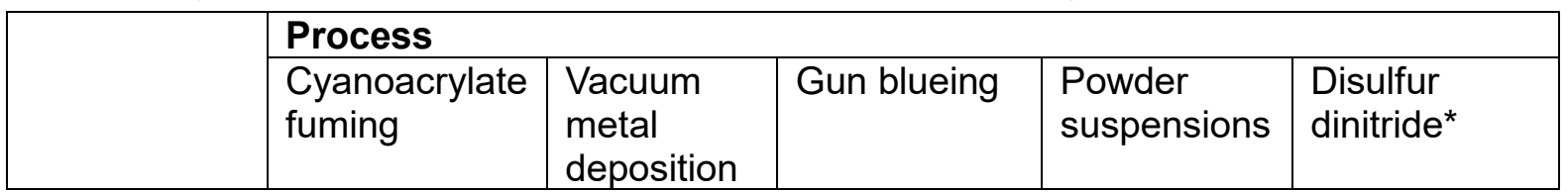




\begin{tabular}{|c|c|c|c|c|c|}
\hline $\begin{array}{l}\text { Preparation } \\
\text { time }\end{array}$ & $\begin{array}{l}45 \text { minutes } \\
\text { maximum } \\
\text { (chamber } \\
\text { purge cycle) }\end{array}$ & $\begin{array}{l}1 \text { hour } \\
\text { maximum } \\
\text { (pump } \\
\text { warm up } \\
\text { cycle) } \\
\end{array}$ & None & None & $\begin{array}{l}\sim 45 \text { minutes } \\
\text { (heater warm } \\
\text { up time) }\end{array}$ \\
\hline $\begin{array}{l}\text { Reagent } \\
\text { stability }\end{array}$ & $\begin{array}{l}1 \text { year } \\
\text { product life } \\
\text { used as } \\
\text { guidance }\end{array}$ & $\begin{array}{l}\text { Indefinite } \\
\text { (stable } \\
\text { metals) }\end{array}$ & $\begin{array}{l}1 \text { year } \\
\text { product life } \\
\text { used as } \\
\text { guidance }\end{array}$ & $\begin{array}{l}\text { } 1 \text { year } \\
\text { product life } \\
\text { used as } \\
\text { guidance }\end{array}$ & $\begin{array}{l}\text { Not } \\
\text { extensively } \\
\text { studied (but } \\
\text { precursor }>3 \\
\text { years old } \\
\text { continues to } \\
\text { develop } \\
\text { marks) }\end{array}$ \\
\hline $\begin{array}{l}\text { Development } \\
\text { time }\end{array}$ & $\begin{array}{l}\sim 1 \text { hour } \\
\text { automatic } \\
\text { cycle }\end{array}$ & $\begin{array}{l}\text { Variable - } \\
\text { (typically } \\
15-20 \\
\text { minutes } \\
\text { per } \\
\text { processing } \\
\text { cycle, } \\
\text { multiple } \\
\text { cycles may } \\
\text { be } \\
\text { required) }\end{array}$ & $\begin{array}{l}30 \text { seconds - } \\
15 \text { minutes } \\
\text { (depending } \\
\text { on } \\
\text { concentration } \\
\text { of solution } \\
\text { used) }\end{array}$ & $<1$ minute & $\begin{array}{l}\sim 45-90 \\
\text { minutes }\end{array}$ \\
\hline $\begin{array}{l}\text { Process } \\
\text { complexity }\end{array}$ & Simple & $\begin{array}{l}\text { High } \\
\text { (requires } \\
\text { skilled } \\
\text { operator) }\end{array}$ & Simple & Simple & $\begin{array}{l}\text { Medium } \\
\text { (experimental } \\
\text { equipment } \\
\text { requires } \\
\text { operator } \\
\text { intervention) }\end{array}$ \\
\hline $\begin{array}{l}\text { Health and } \\
\text { safety issues }\end{array}$ & $\begin{array}{l}\text { None (if using } \\
\text { carbon filtered } \\
\text { fuming } \\
\text { chamber) }\end{array}$ & None & $\begin{array}{l}\text { Contains } \\
\text { toxic } \\
\text { selenious } \\
\text { acid } \\
\left(\mathrm{He}_{2} \mathrm{SeO}_{3}\right)\end{array}$ & None & $\begin{array}{l}\text { Vacuum } \\
\text { conditions } \\
\text { required to } \\
\text { avoid ignition } \\
\text { of precursor } \\
\text { on heating, } \\
\text { residual } \\
\text { fumes } \\
\text { require } \\
\text { venting to } \\
\text { extracted } \\
\text { area }\end{array}$ \\
\hline
\end{tabular}

* Observations relate to experimental equipment used in this study only, not to commercial equipment now available

Table 2. Comparison of the processes used in the comparative study

\section{Experimental}

A series of experiments were conducted to explore different aspects of the performance of $\mathrm{S}_{2} \mathrm{~N}_{2}$ in comparison to other processes, including specificity, sensitivity, effect of ageing and ability to develop fingermarks on samples exposed to extreme conditions. The experimental methodology was approved via the internal 
Ethics process and all donors read and signed consent forms prior to participating in the study.

\section{Sensitivity:}

The sensitivity of the processes was investigated using an extended depletion series. Three different donors who had not washed their hands for over 30 minutes rubbed their hands together to evenly distribute secretions and deposited depletion series of 36 consecutive 'natural' marks running over both sides of 4 brass samples. Fingermarks were aged for 2 days before being processed.

\section{Specificity:}

A multiple donor study was conducted using 22 different donors who deposited a single fingermark from a different finger on each of 4 panels of brass, bronze, copper and stainless steel, with hands being rubbed together after each finger had been used once. Marks were left to age for 1 week before being processed.

\section{Effect of fingermark age:}

Five different donors deposited the $1^{\text {st }}, 5^{\text {th }}$ and $10^{\text {th }}$ mark of a 10 mark depletion series on each of 4 panels of brass, bronze, copper and stainless steel, with hands being rubbed together after each finger had been used once. The other fingermarks in the depletion series were deposited on a 'sacrificial' sheet of paper, Figure 3. This enabled the effect of depletions to be evaluated on the small test samples.

Fingermarks were left to age for 1 day, 1 week, 1 month and 3 months before being processed.

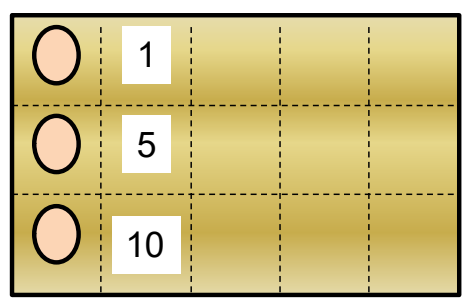

Metal sample

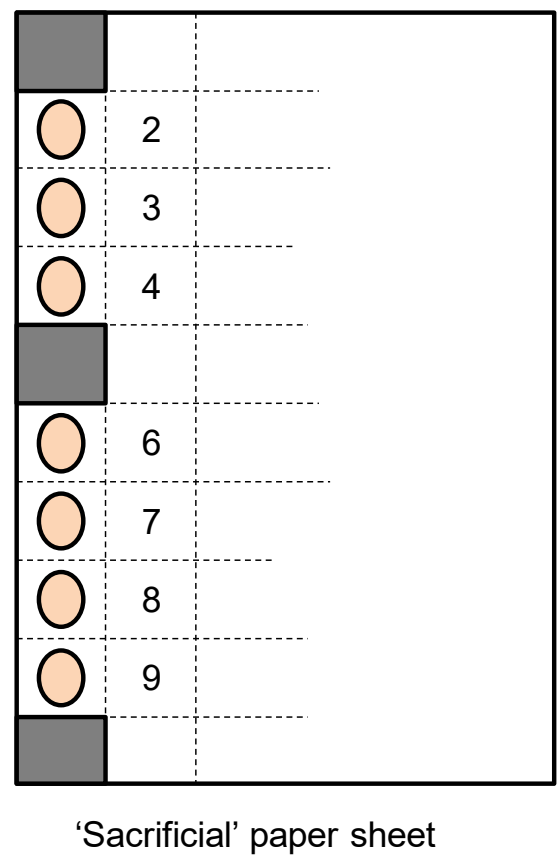

Figure 3. Schematic diagram to show order of deposition of marks, enabling the trends of a depletion series to be observed on a sample of restricted size 


\section{Effect of water washing:}

$\mathrm{S}_{2} \mathrm{~N}_{2}$ has been previously shown [35] to be capable of developing marks after samples have been washed with water, and therefore this experiment explored this in comparison to other processes. The same procedure and number of donors as outlined for the ageing experiment above was used. Deposited fingermarks were left on the samples for 10 minutes, 1 hour, 1 day and 1 week before being washed and scrubbed in a mixture of water and detergent (Fairy Liquid) using a nylon bristled brush. They were then rinsed and immersed in purified water before being dried in air and processed.

\section{Effect of solvent washing:}

A solvent wash (acetone) was investigated as a process which may remove different fingermark constituents to the water/detergent wash described above. The same procedure and number of donors as outlined above was used. Fingermarks were left on the samples for 10 minutes, 1 hour, 1 day and 1 week before acetone was applied to the sample and rubbed vigorously across the surface with a paper tissue. The samples were then allowed to dry in air before being processed.

\section{Effect of heating:}

The effect of exposure to high temperatures for different periods of time on fingermark recovery was explored. The same procedure and number of donors as outlined above was used. Fingermarks were left on the samples for 1 day before being placed in a Nabertherm LE14/11 furnace at $600^{\circ} \mathrm{C}$ for 5 minutes, 15 minutes, 1 hour, and 4 hours. The samples were then removed from the furnace and allowed to cool before being processed.

\section{Grading and imaging}

Fingermarks were graded using the $0-4$ grading system proposed by the Home Office $[40,41]$, Table 3.

\begin{tabular}{|c|l|}
\hline Score & Level of detail \\
\hline 0 & No evidence of fingermark \\
\hline 1 & Weak development; evidence of contact but no ridge detail \\
\hline 2 & $\begin{array}{l}\text { Limited development; ridge detail present in up to } 1 / 3 \text { of mark but probably cannot } \\
\text { be used for identification purposes }\end{array}$ \\
\hline 3 & $\begin{array}{l}\text { Strong development; between } 1 / 3 \text { and } 2 / 3 \text { of mark contains ridge detail; } \\
\text { identifiable finger mark }\end{array}$ \\
\hline
\end{tabular}


Table 3. Outline grading scheme used in these studies

Visible developed fingermarks were graded using an eye glass and the variable lighting conditions provided by room lighting and from diffuse light from a window. Fluorescent marks were graded from images taken of the test panels under the conditions summarised below.

Images of the panels were captured using a Sony $\alpha 77$ DSLR fitted with a Minolta $50 \mathrm{~mm}$ macro lens mounted on a Kaiser RSI copystand with white side lights set at $45^{\circ}$. A blue Crimelite 82S (Foster + Freeman, Evesham, UK) and Schott glass GG495 camera filter were used to capture images of fingermarks dyed using BY40. Further examinations were conducted using a VSC6000 document examination workstation (Foster + Freeman, Evesham, UK) which provided additional lighting modes including co-axial light.

\section{Microscopy}

The microstructure of developed marks was studied using scanning electron microscopy. Samples were prepared from brass, copper and stainless steel by cutting $8 \mathrm{~mm}$ diameter discs from metal sheets using a hole punch. Fingermarks were laid across each disc and aged for 1 day before being treated with $\mathrm{S}_{2} \mathrm{~N}_{2}$. The discs were mounted on aluminium stubs and placed into a Pemtron PS-230 scanning electron microscope (SEM). Because of the conductive nature of the substrate, it was not considered necessary to apply a conductive gold coating to the samples to prevent charging.

\section{Results and discussion}

Sensitivity:

Figure 4 shows the totals of the grades of each mark in the depletion series, combining the results of the marks from three donors. 


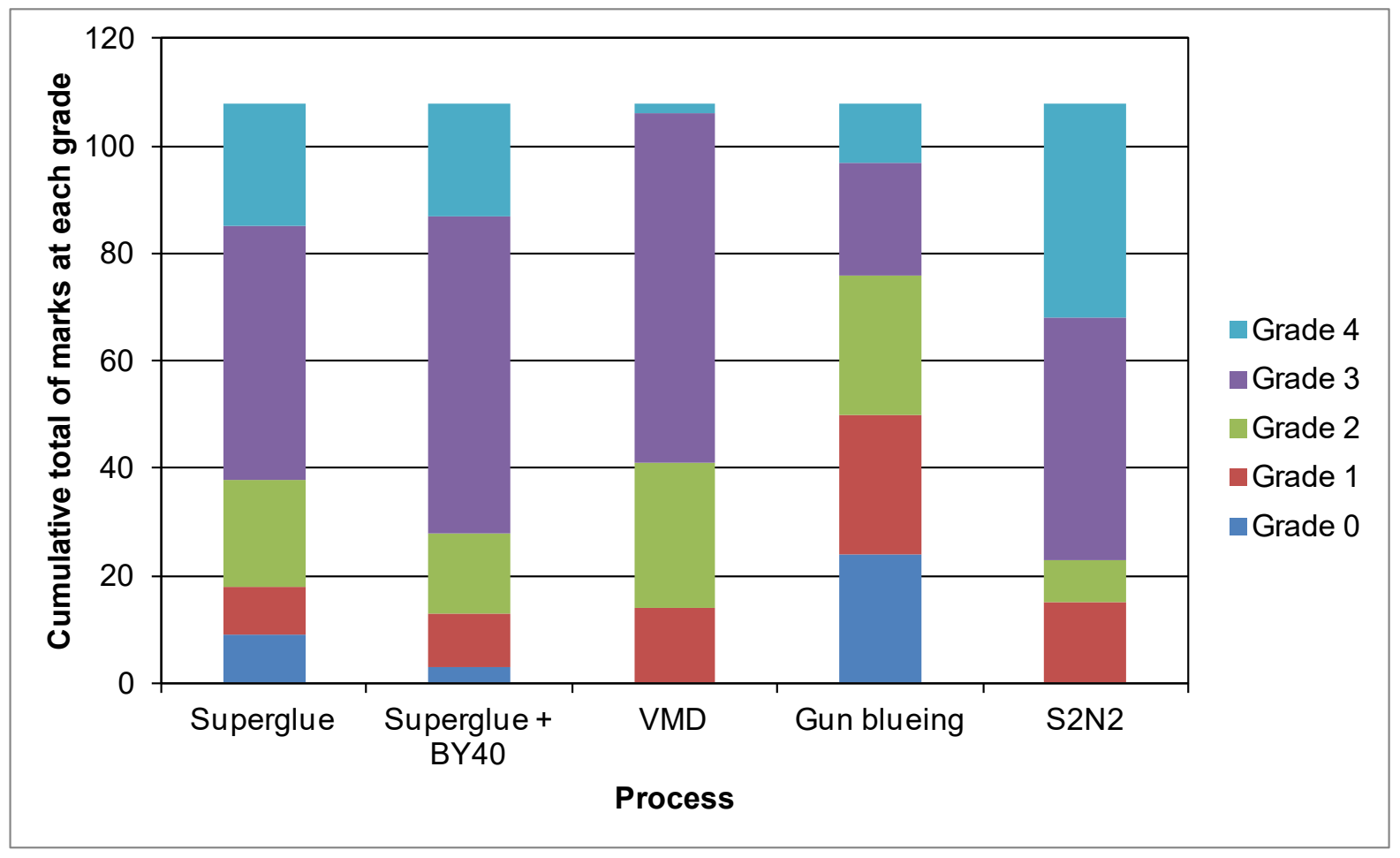

Figure 4. Cumulative totals of marks at each grade, combining results of the three 36-mark depletion series on brass developed using different processes.

Superglue fuming/BY40 and $\mathrm{S}_{2} \mathrm{~N}_{2}$ continued to develop marks considered of identifiable quality from the first to the $36^{\text {th }}$ mark in the series for two out of the three donors and develop the highest combined totals of marks graded 3 or 4 .

Gun blueing undergoes the most rapid fall off in grade quality for developed marks, however this does not become noticeable until after the $10^{\text {th }}$ mark in the depletion series and gun blueing is still a reasonably sensitive process until after the $20^{\text {th }}$ depletion. Vacuum metal deposition is capable of developing marks close to the end of the depletion series, but on average these are graded lower than those developed using $\mathrm{S}_{2} \mathrm{~N}_{2}$ and superglue fuming.

The first mark in each depletion series for one donor are illustrated in Figure 5, together with an image for the $36^{\text {th }}$ mark where this was successfully developed.
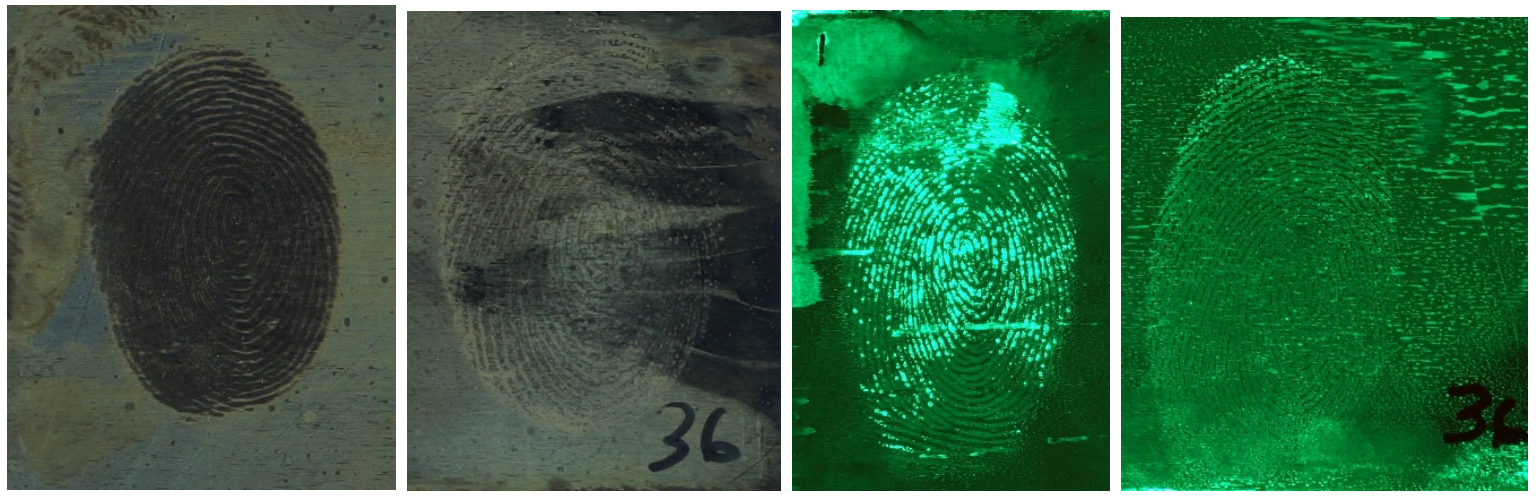
a)

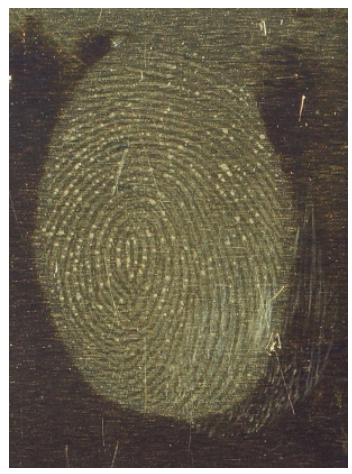

e) b)

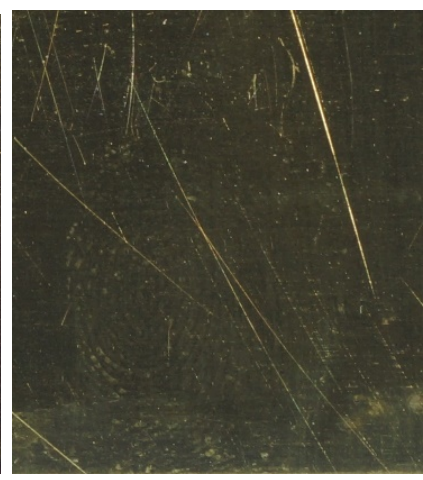

f) c)

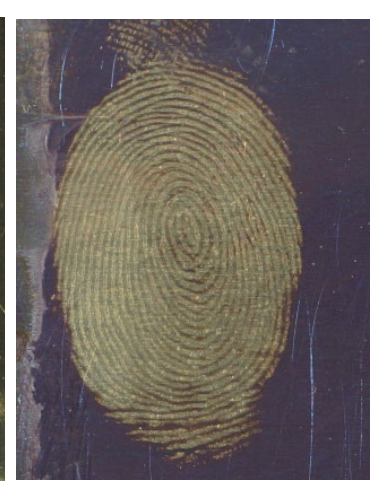

g) d)

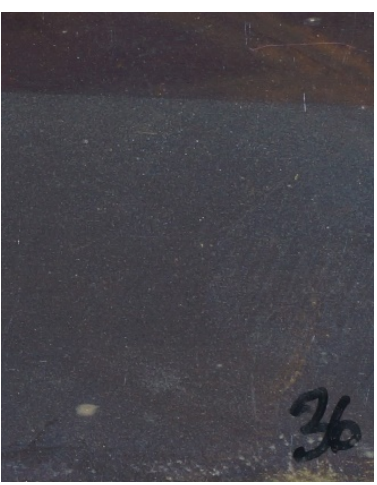

h)

Figure 5. Marks 1 and 36 from depletion series on brass developed using: a-b) $S_{2} N_{2}$, $c-d)$ superglue fuming and Basic Yellow 40 dye, e-f) vacuum metal deposition, and $g$-h) gun blueing

Specificity:

The number of fingermarks from the 22 different donors that were graded 3 or 4 is illustrated in Figure 6.

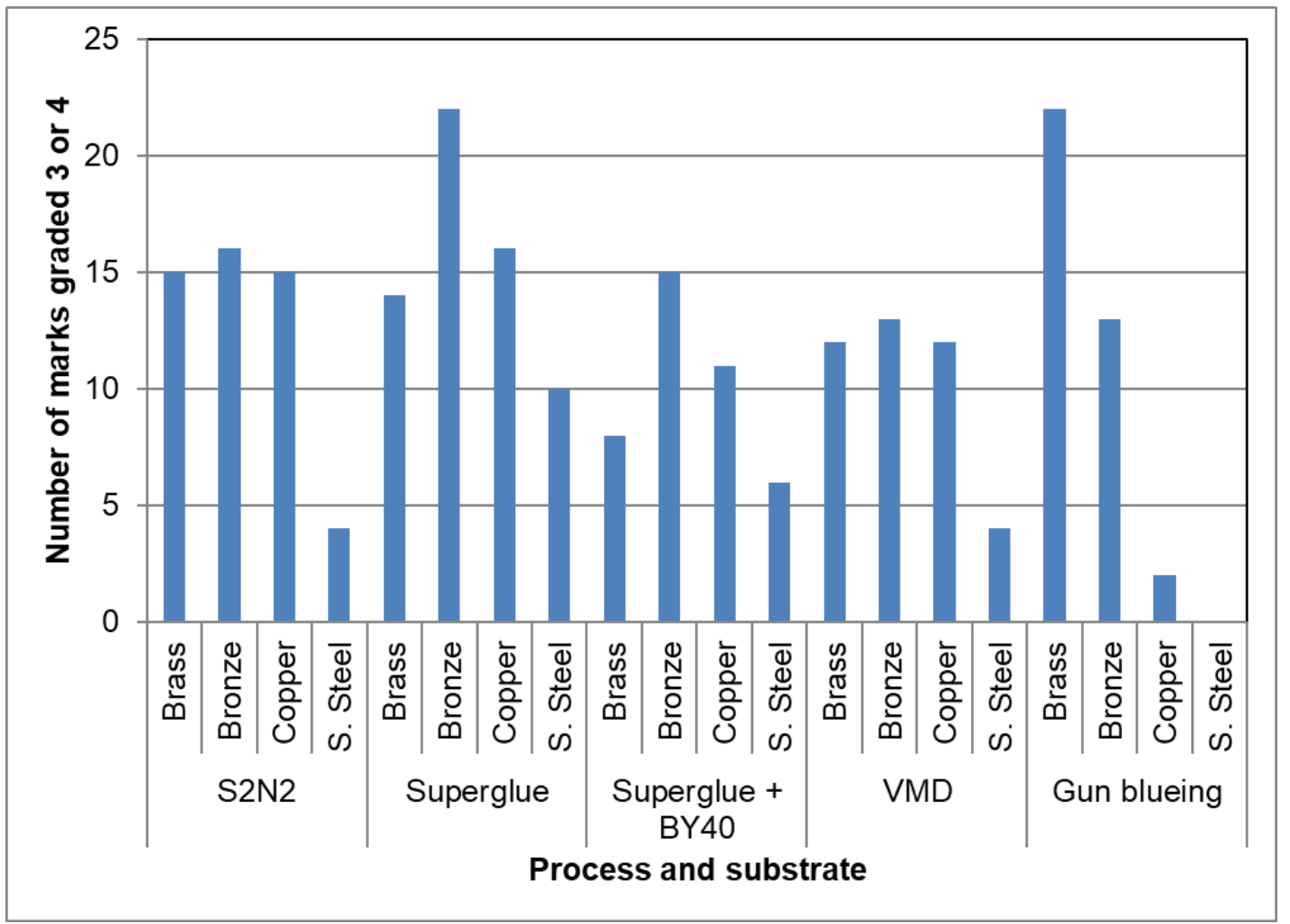

Figure 6. The number of fingermarks graded 3 or 4 developed by the different processes used in the multiple donor study.

Nearly all processes are capable to developing marks graded 3 or 4 from at least $50 \%$ of the donors on the copper-based alloys, the exception being gun blueing on 
copper. None of the processes worked as well on stainless steel, and gun blueing did not work at all because the chromium oxide layer on the surface protects the underlying metal from the gun blueing solution. For this reason carbon-based black powder suspension was used in place of gun blueing for all subsequent experiments involving stainless steel.

The results obtained after dyeing superglue fumed marks with BY40 were sometimes inferior to those seen under white light with optimum viewing angles, partly attributable to background staining by the BY40 dye. Although the cleaning regime used was thought to be rigorous, it does not always remove residues from the protective polymer films originally present on the metals and these can sometimes interfere with visualisation of marks.

In many cases the quality of the developed mark (especially those by $\mathrm{S}_{2} \mathrm{~N}_{2}$ ) could be improved significantly by using some of the more specialised lighting modes on the VSC6000, such as co-axial light. An example of an improvement in the appearance of $\mathrm{S}_{2} \mathrm{~N}_{2}$ marks under different lighting conditions is shown in Figure 7.

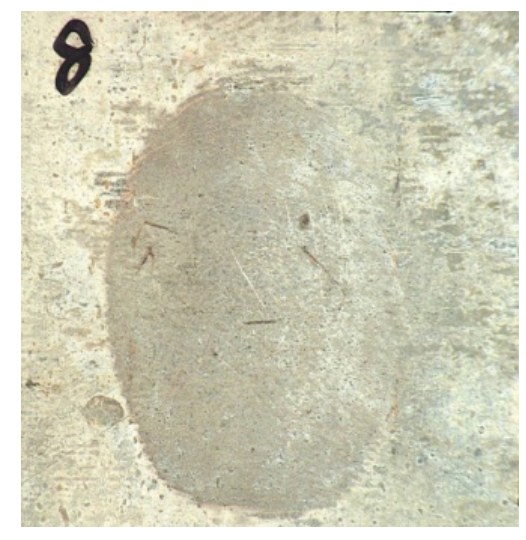

a)

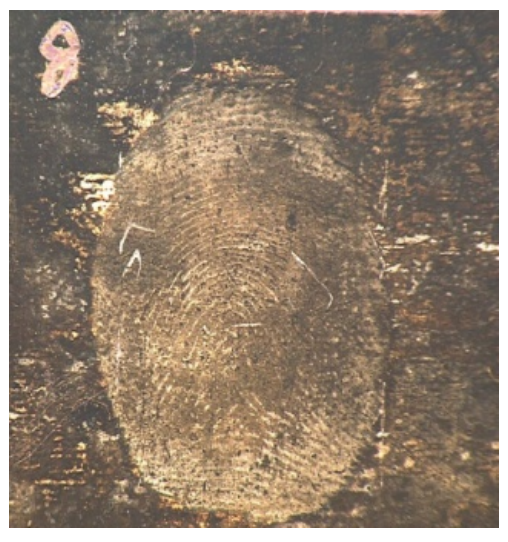

b)

Figure 7. Examples of how the observed quality of marks can be changed by different lighting conditions: a) mark developed using $S_{2} N_{2}$ on bronze, lit with $45^{\circ}$ white lights; b), as a), but illuminated under co-axial lighting

\section{Effect of fingermark age:}

The effect of fingermark age on the quality of the marks enhanced on each of the four surfaces is illustrated in Figure 8. 


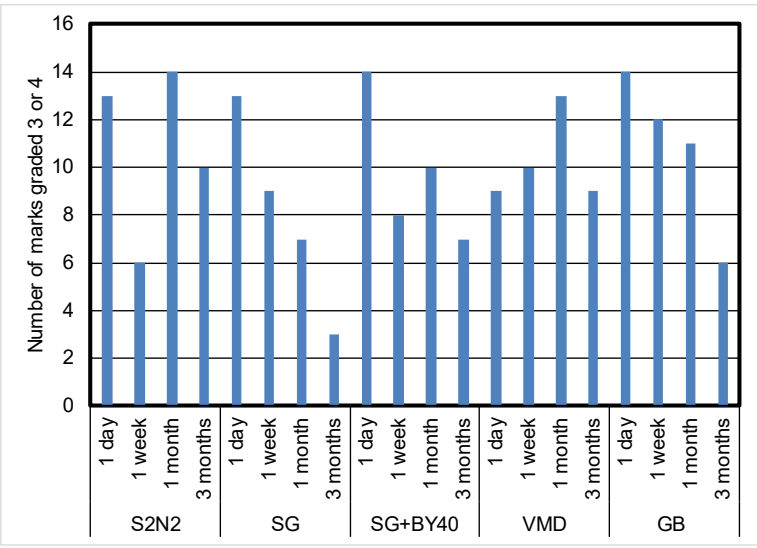

Brass

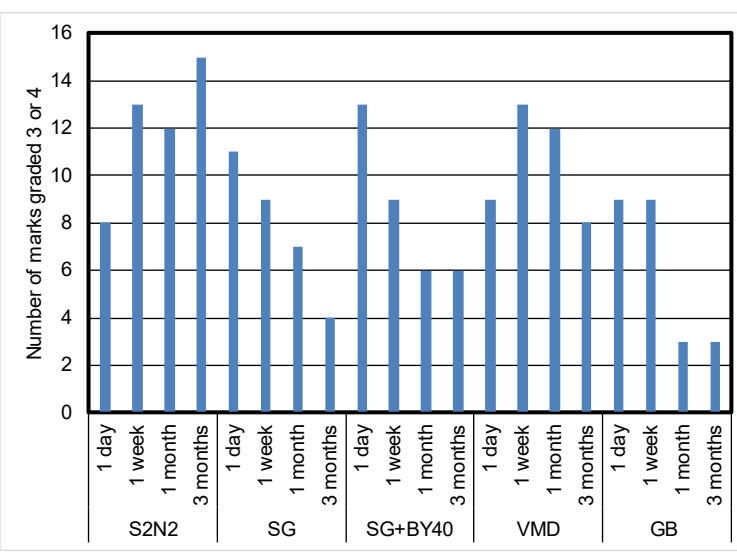

Copper

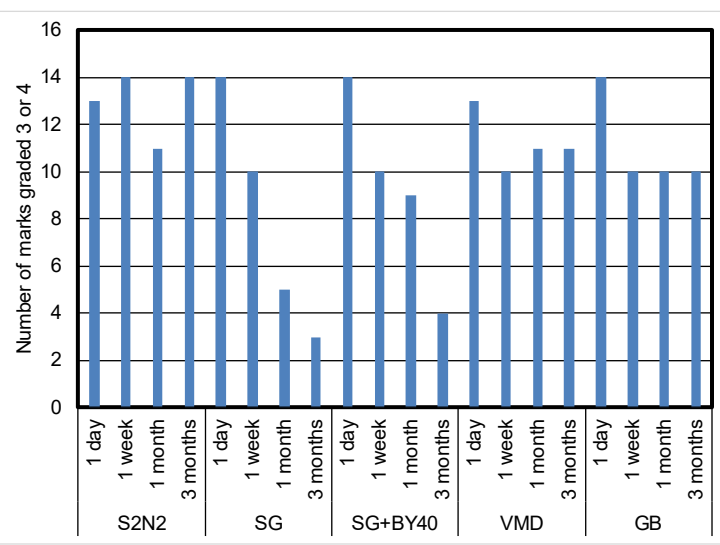

Bronze

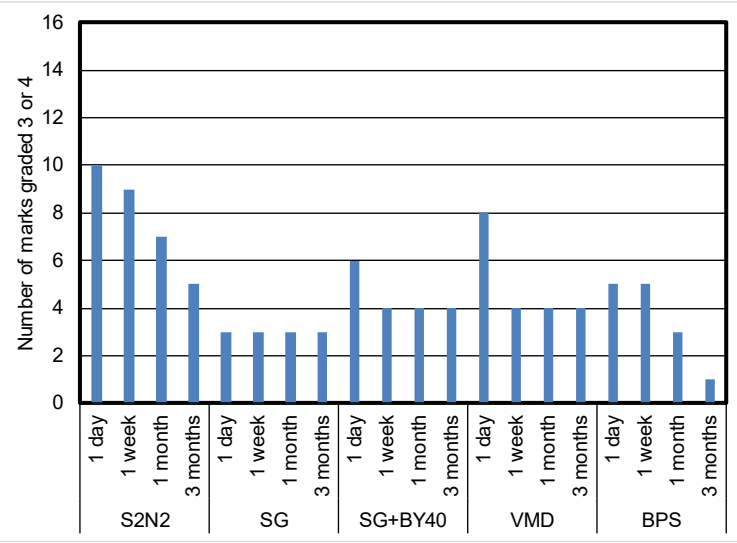

Stainless steel

Figure 8. Number of fingermarks graded 3 and 4 developed by each of the processes used in the study after ageing for different periods of time on a) brass, $b$ ) bronze, c) copper, and d) stainless steel

In general, on copper-based metal surfaces nearly all processes developed $50 \%$ or greater of the deposited marks to a high quality across most of the time scales studied. This is possibly because there are more chemical interactions that can occur between the fingermark and the substrate on these materials resulting in more species being present for visualisation processes to interact with. $\mathrm{S}_{2} \mathrm{~N}_{2}$ and VMD appear to be least affected by the age of the mark, with $\mathrm{S}_{2} \mathrm{~N}_{2}$ in particular developing nearly all fingermarks to grade 3 or 4 after 3 months. In contrast, the effectiveness of superglue fuming and gun blueing progressively decrease over time, which is in accordance with previous observations that superglue fuming is less effective when marks have dried out [42]. Examples of marks after 1 day and 3 months are given in Figure 9. It can be seen that the marks aged for 3 months tend to be lower in contrast and less well defined than the equivalent marks aged for 1 day. 


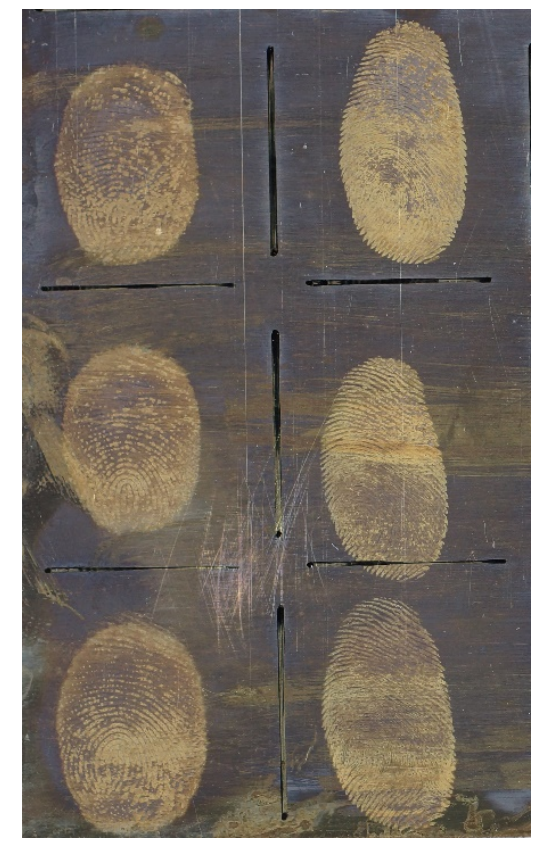

a) 1 day

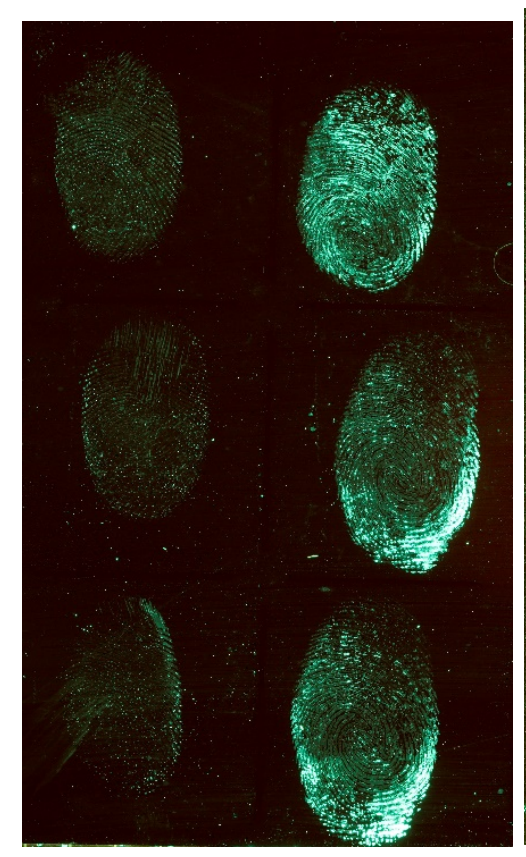

b) 1 day

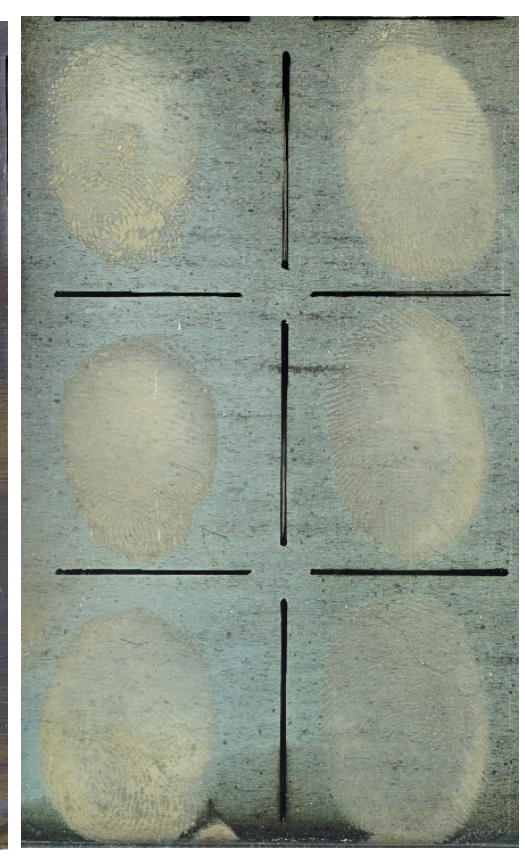

3 months

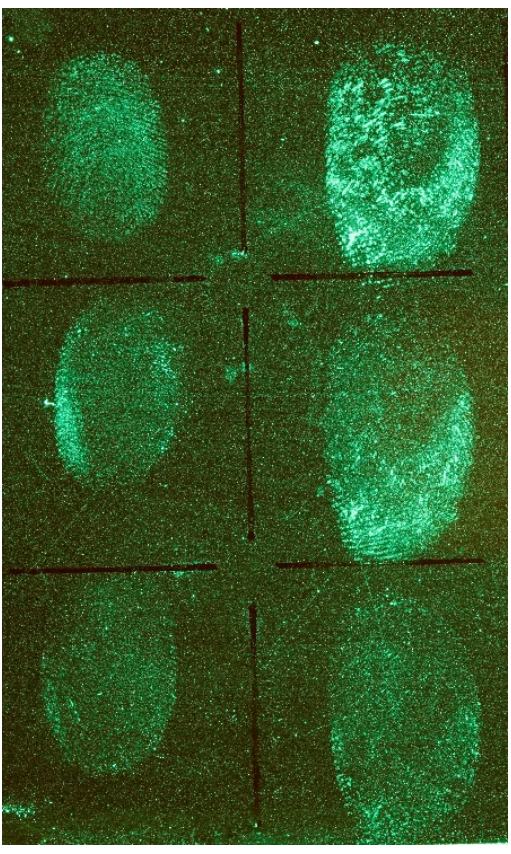

3 months 


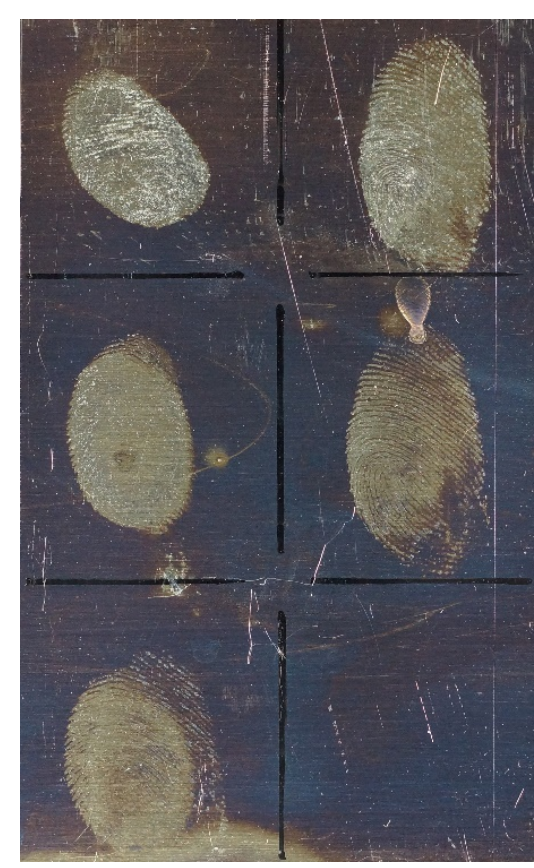

c) 1 day

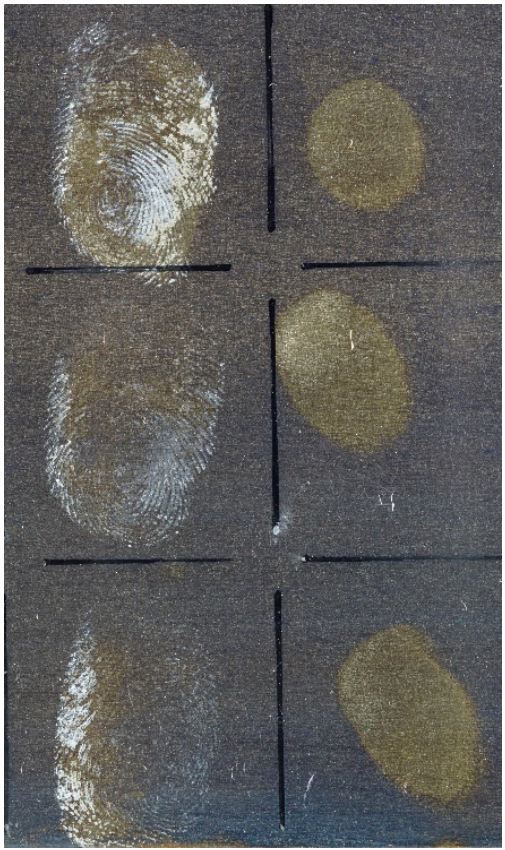

3 months

Figure 9. Marks 1, 5 and 10 in the depletion series developed after 1 day and 3 months using a) $\mathrm{S}_{2} \mathrm{~N}_{2}$ on brass, b) superglue fuming and Basic Yellow 40 on bronze, c) VMD on brass

The performance of all the processes is reduced on stainless steel, with $\mathrm{S}_{2} \mathrm{~N}_{2}$ consistently developing more high quality marks than other processes but decreasing in effectiveness as marks age.

\section{Effect of water washing:}

The number of fingermarks graded 3 and 4 developed after water washing is shown in Figure 10 for each of the four metal surfaces studied.

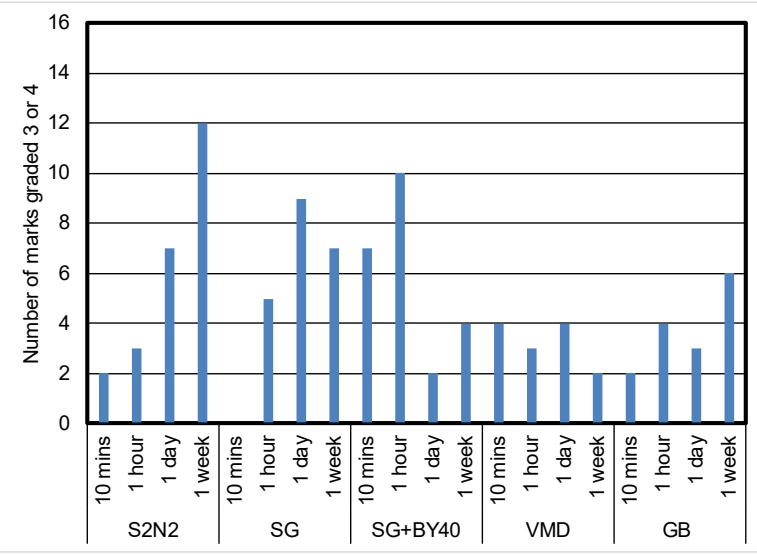

Brass

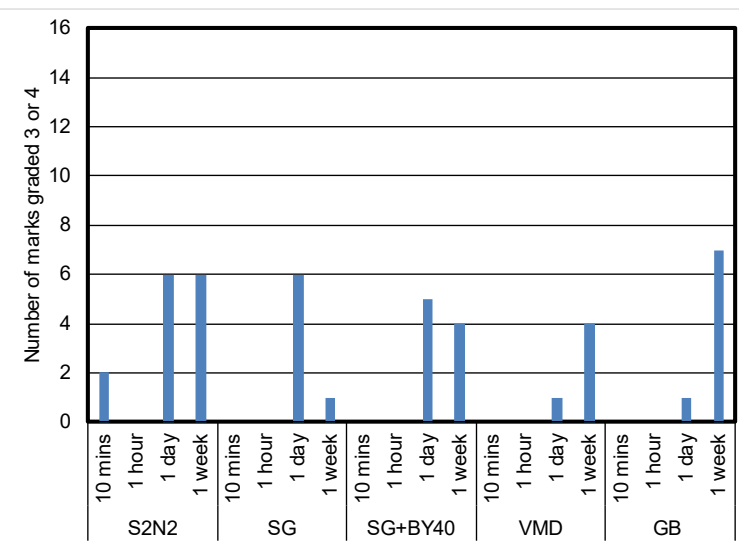

Bronze 


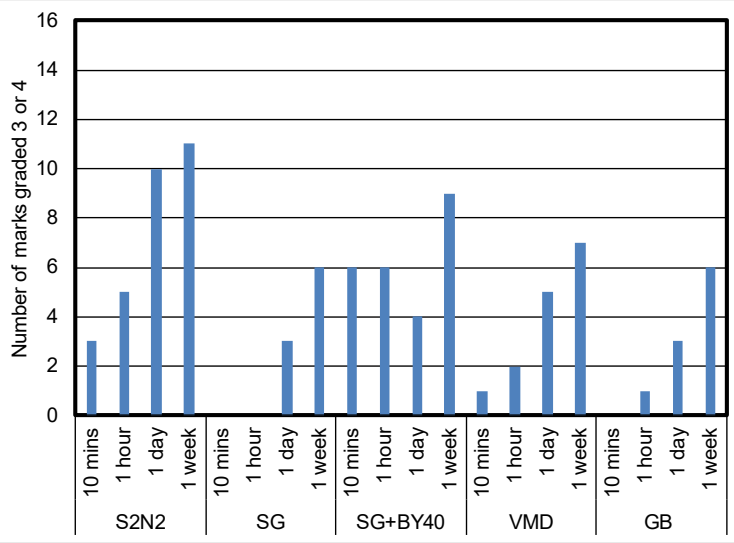

Copper

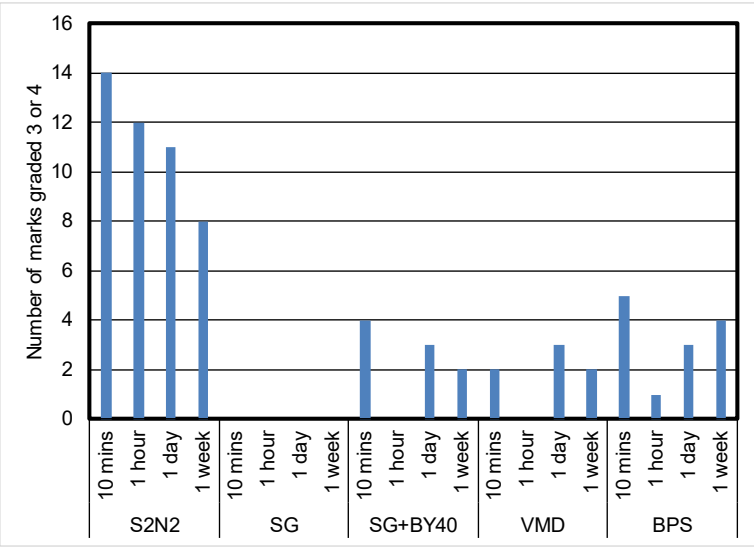

Stainless steel

Figure 10. Number of fingermarks graded 3 and 4 developed by each of the processes used in the study after washing with water/detergent on a) brass, $b$ ) bronze, c) copper, and d) stainless steel

It can be seen that despite the aggressive nature of the cleaning method employed, fingermarks may still be developed on each of the four metals, and all of the visualisation processes used were capable of developing marks in certain scenarios, Figure 11. This supports previous observations of Cohen et al [43] showing fingermarks can be more resilient than expected to cleaning regimes, although Cohen's work focused on painted window frames as opposed to untreated metals.

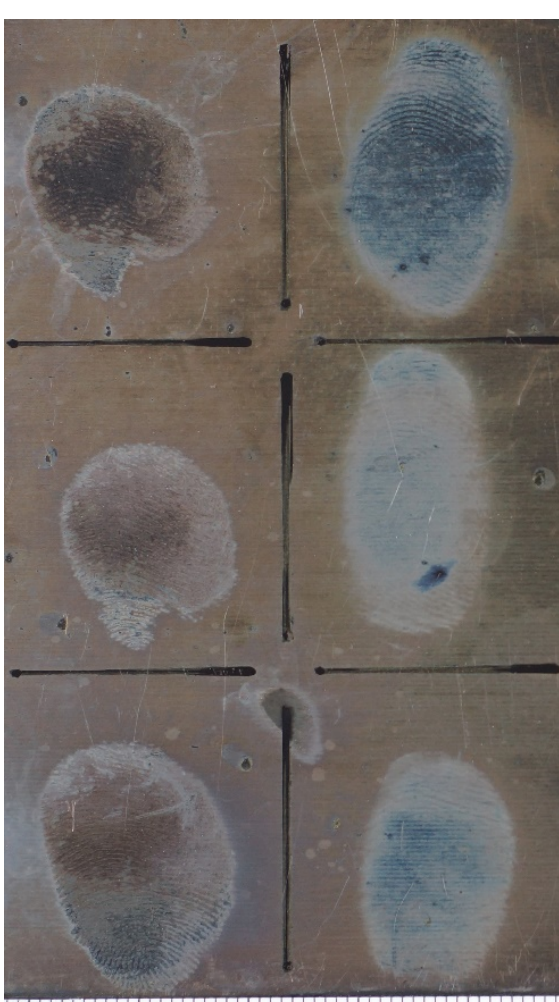

a)

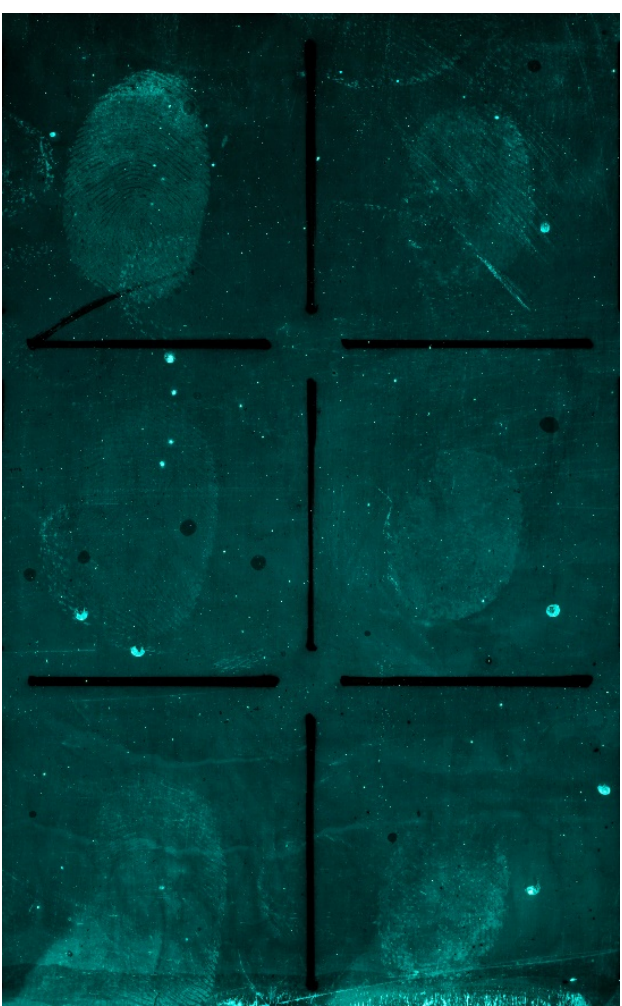

b) 


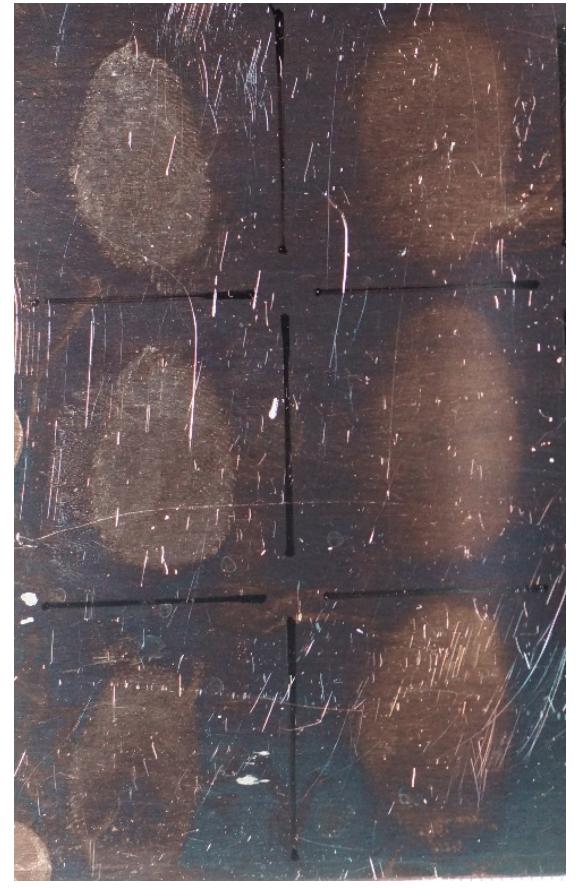

c)

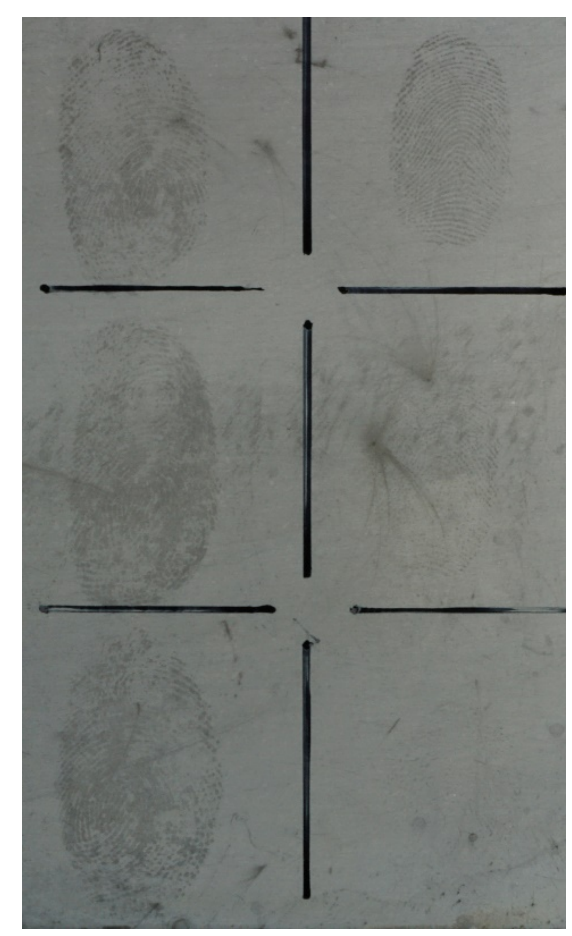

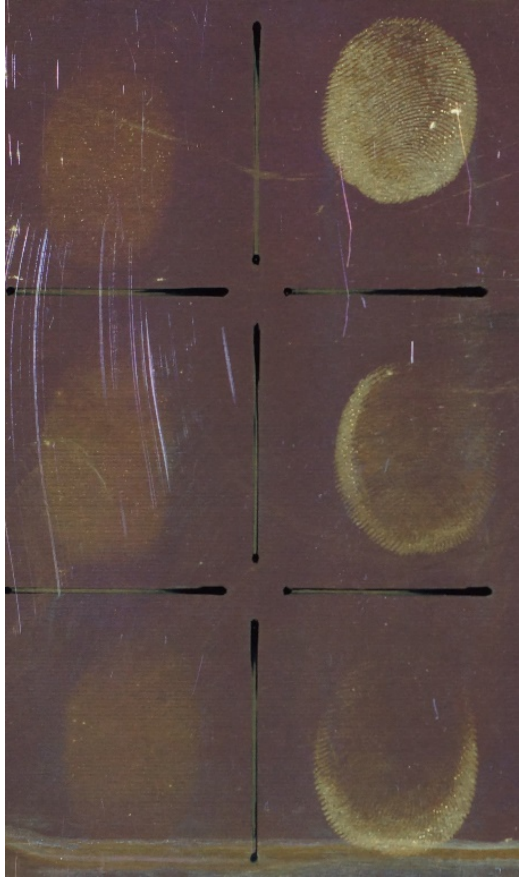

d)

e)

Figure 11. Marks 1,5 and 10 in the depletion series 1 week before water/detergent washing then developed using a) $\mathrm{S}_{2} \mathrm{~N}_{2}$ on brass, b) superglue fuming and Basic Yellow 40 on bronze, c) VMD on bronze, d) gun blueing on copper, and e) black powder suspension on stainless steel.

$\mathrm{S}_{2} \mathrm{~N}_{2}$ is the only process that developed potentially identifiable marks on every metal for almost every ageing period (the exception being marks on bronze aged for 1 hour 
before washing). On copper-based alloys, the effectiveness of $\mathrm{S}_{2} \mathrm{~N}_{2}$ appears to increase the longer that the mark remains on the surface. This is consistent with previous results [35] and also to be expected if (as suggested) $\mathrm{S}_{2} \mathrm{~N}_{2}$ is targeting areas of surface corrosion instead of fingermark residue. Although the exact mechanism of corrosion during the fingermark-surface reaction has not been conclusively demonstrated $[12,14]$ it seems reasonable that any interaction will be more pronounced over a longer period of exposure.

Similar trends are seen for some of the other processes used which may be due to increased interaction between the fingermark and the surface, as proposed for $\mathrm{S}_{2} \mathrm{~N}_{2}$, or it may be due to the mark drying out on the surface, making it more resilient to subsequent application of water/detergent.

The dyeing of superglue fumed marks with BY40 does increase the number visualised. Although this is an expected outcome, this was not observed in previous parts of the study. It is possible that the samples used in later stages of the work were more rigorously cleaned resulting in less residue remaining on the background and correspondingly less background development. However, it should also be noted that many of these fluorescent marks are extremely faint and were only found when reviewing photographs speculatively taken of the treated surface. Such marks would probably not be detected in operational casework because there is no visual indicator that a mark is present to be photographed.

On stainless steel, $\mathrm{S}_{2} \mathrm{~N}_{2}$ appears considerably more effective than the other processes although in contrast to results on copper-based alloys fewer fingermarks are recovered as the time on the surface before washing increases. The development mode of $\mathrm{S}_{2} \mathrm{~N}_{2}$ on stainless steel is also noticeably different, instead of $(\mathrm{SN}) \times$ polymer being deposited on the ridges it is preferentially deposited on the background, giving it a blueish tinge while the ridges appear a paler colour. Because stainless steel is a corrosion resistant alloy, it is unlikely that any corrosion interaction is occurring between the fingermark and the metal. This may explain the lack of development observed with superglue fuming, which relies on fingermark constituents being present to initiate polymerisation, as opposed to processes such as VMD and powder suspensions which are sensitive to changes in the surface properties.

\section{Effect of acetone washing:}

The number of fingermarks graded 3 and 4 developed after washing with acetone and rubbing with a tissue is shown in Figure 12 for each of the four metal surfaces studied. 


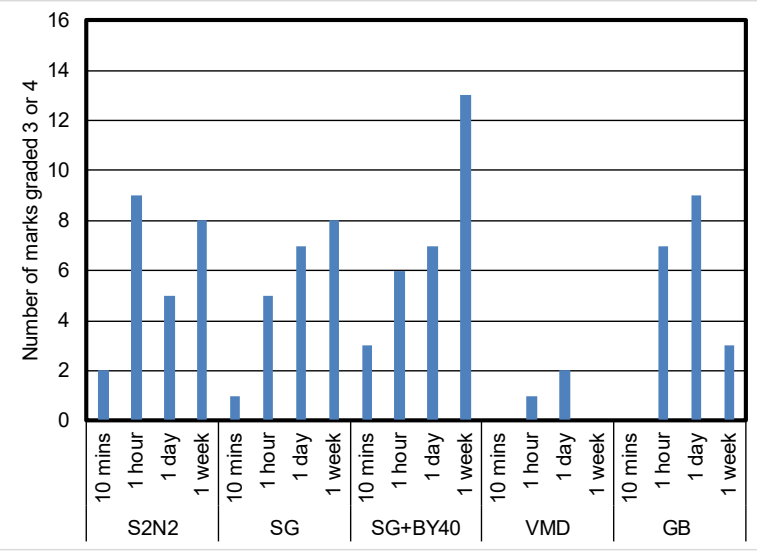

Brass

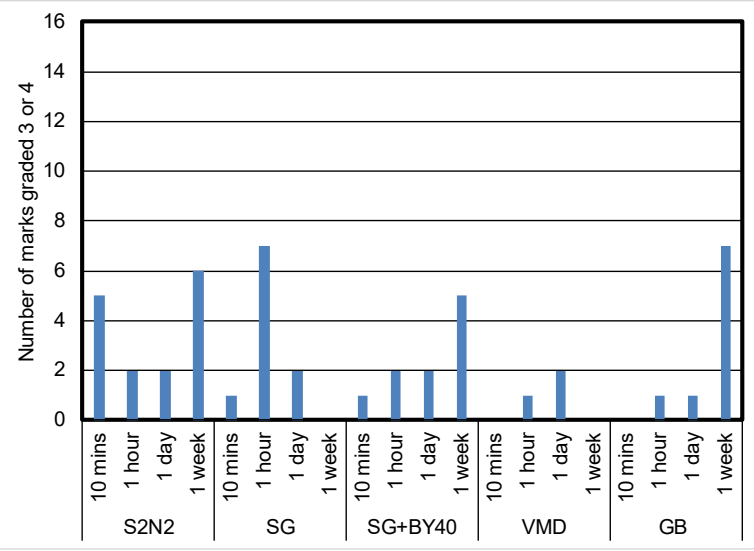

Copper

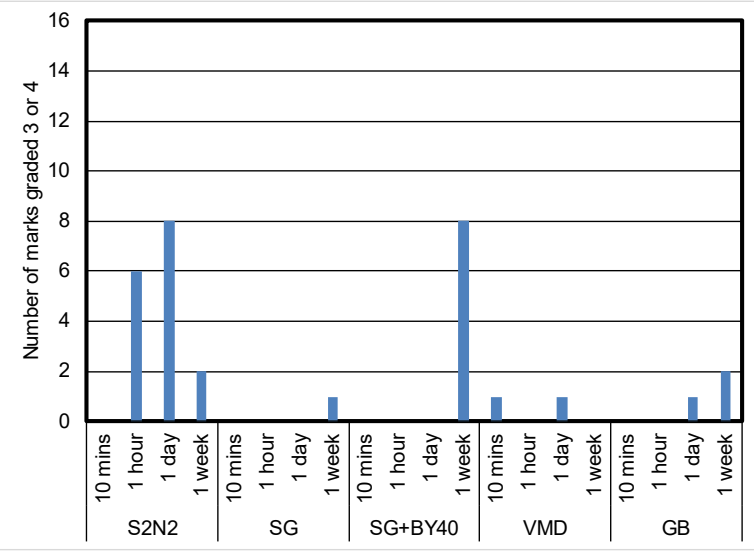

Bronze

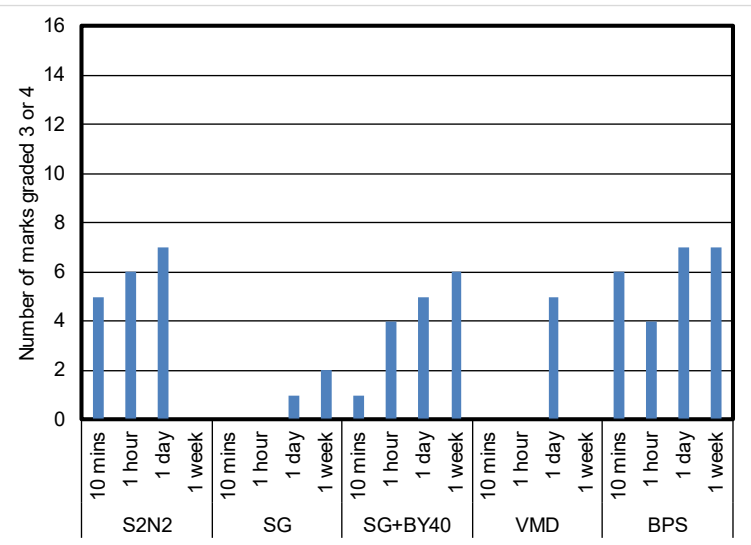

Stainless steel

Figure 12. Number of fingermarks graded 3 and 4 developed by each of the processes used in the study after washing with acetone on a) brass, b) bronze, c) copper, and d) stainless steel

Washing with acetone is a far more aggressive form of cleaning than scrubbing with water/detergent, but again several marks do survive this treatment and the recovery rate is not zero.

Similarly to the water wash results, $\mathrm{S}_{2} \mathrm{~N}_{2}$ appears to give the best overall performance, with some marks being developed using this process on all four types of substrate. Carbon-based powder suspension also appears to be an effective process for marks deposited on stainless steel, although it has been shown in other studies [39] to perform poorly on copper-based alloys. Acetone washing has a noticeably detrimental impact on the effectiveness of VMD, with very few high quality marks being developed on any of the metals studied. Examples of marks developed after the acetone wash are shown in Figure 13. 


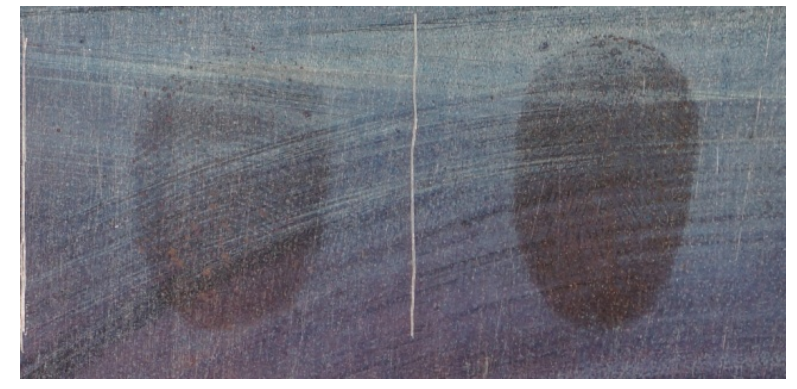

a)

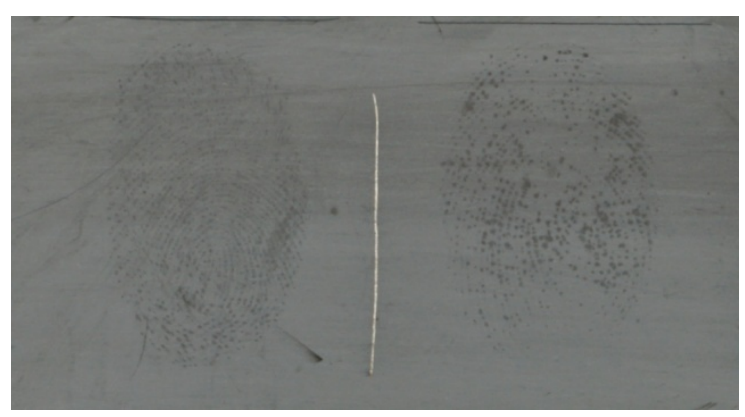

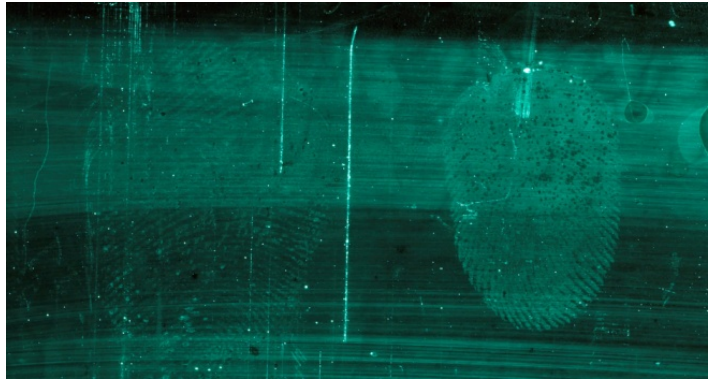

b)

c)

Figure 13. Fingermarks aged for 1 week before washing with acetone, then developed using a) $\mathrm{S}_{2} \mathrm{~N}_{2}$ on bronze, b) superglue fuming and Basic Yellow 40 on brass, c) black powder suspension on stainless steel.

Although superglue fuming and dyeing with BY40 does develop marks after both water/detergent and acetone washing, it should again be noted that these are significantly fainter than the marks developed on the aged samples and were not seen by eye during fluorescence examination.

In common with trends observed for the water washed samples, there appears to be a general increase in the number of marks visualised the longer the fingermark remains on the surface prior to being washed off.

\section{Effect of heating:}

Heating was the most damaging of the three processes applied. For copper and bronze, after an hour of exposure to $600^{\circ} \mathrm{C}$ a thin black oxide layer began to form on the surface and this was much more pronounced after 4 hours. This layer became flaky on cooling and was brushed from the surface using a soft animal hair brush prior to treatment. The formation of a flaky oxide layer has also been observed in studies by Wightman et al [44]. In the case of brass, the surface became progressively more matt in appearance as heating time increased, but there was no obvious formation of a surface layer. Stainless steel became more discoloured as heating times increased. On all types of metal fingermarks were developed to some extent by the action of heat alone, as observed by Wightman and co-workers $[12,44]$ and shown in Figure 14. 


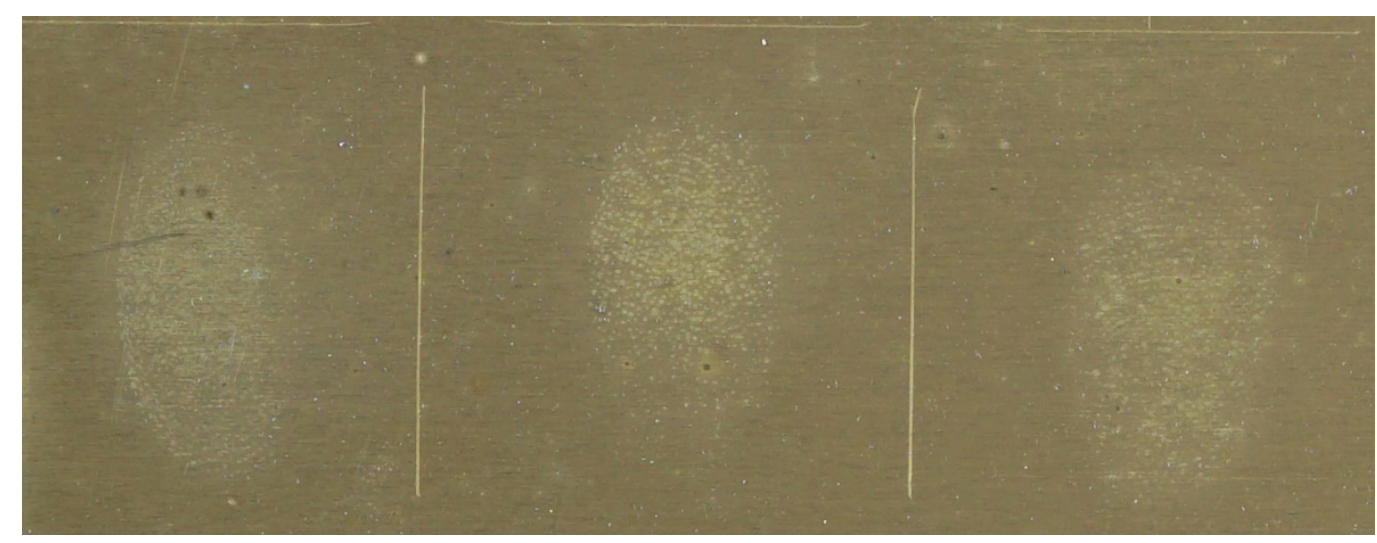

Figure 14. Fingermarks developed on brass by exposure to temperatures of $600^{\circ} \mathrm{C}$ for 15 minutes, prior to any visualisation process being applied.

The quality of these 'pre-developed' fingermarks was disregarded when scoring the samples after treatment, and only marks where it was considered that the chemical treatment had developed additional ridge detail or added contrast were ascribed scores. It was not always easy to make a judgement regarding whether a mark had been actually been enhanced by the chemical treatment or the ridge detail present had been developed by the prior action of heat. The results of grading marks improved by the chemical treatment and discounting heat-developed marks where the ridge detail had not been changed by processing are shown in Figure 15.
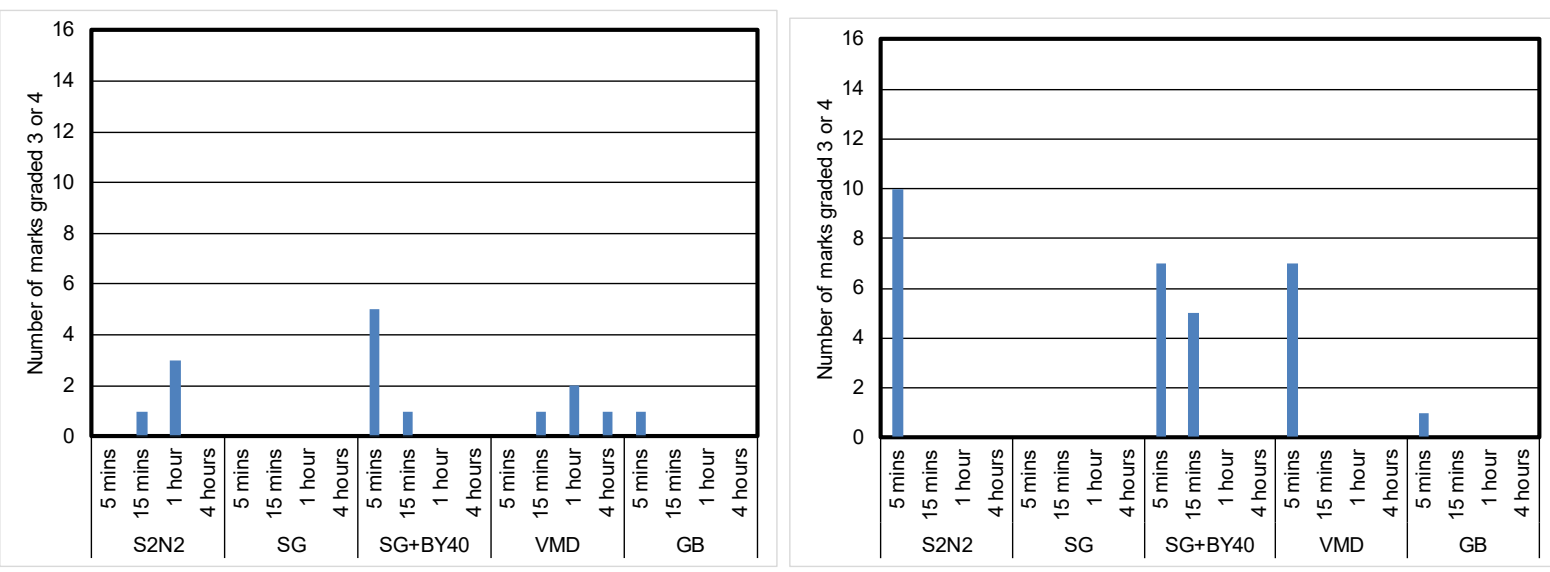

\section{Brass}

\section{Bronze}
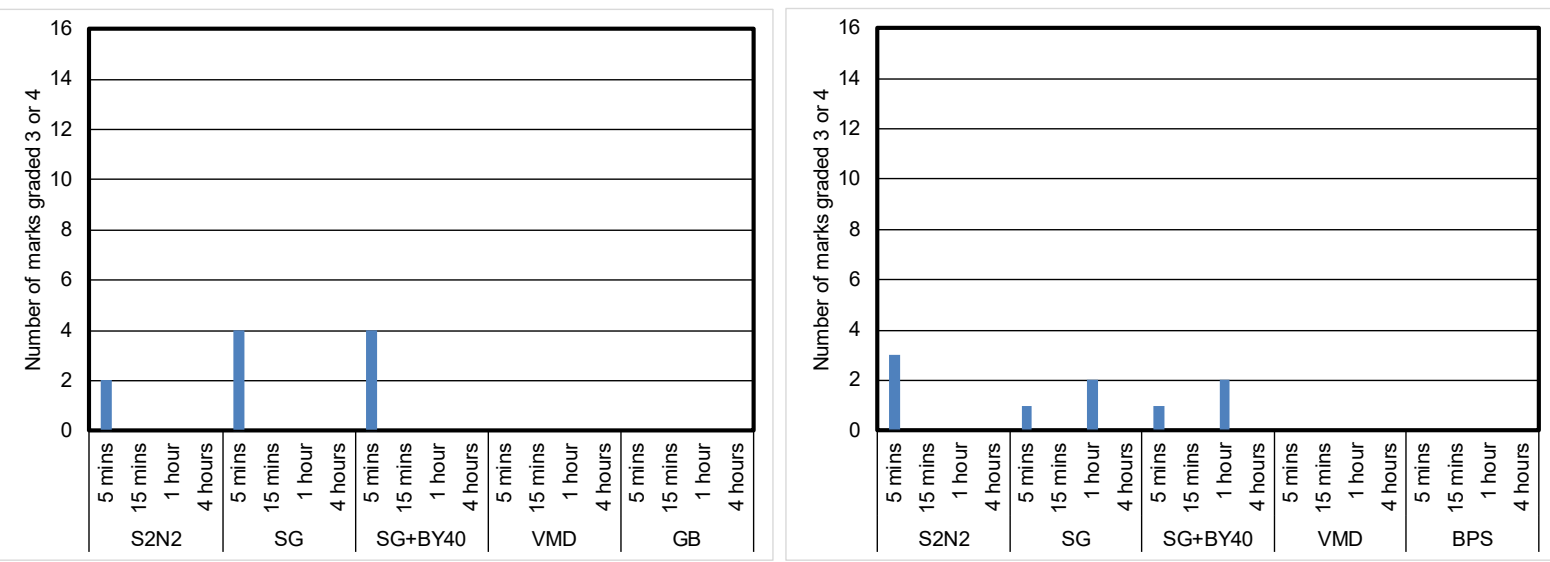
Figure 15. Number of 'value added' fingermarks graded 3 and 4 developed by each of the processes used in the study after heating to $600^{\circ} \mathrm{C}$ for different periods of time on a) brass, b) bronze, c) copper, and d) stainless steel

In general, after 5 minutes exposure to $600^{\circ} \mathrm{C}$, few additional marks are visualised on any of the surfaces studied. The most effective processes in developing additional marks on metals are $\mathrm{S}_{2} \mathrm{~N}_{2}$ and superglue fuming, with examples being presented below.

Marks developed on bronze using $\mathrm{S}_{2} \mathrm{~N}_{2}$ are illustrated in Figure 16.

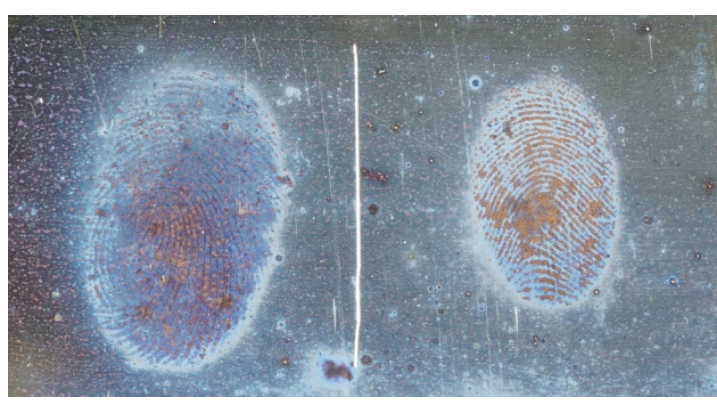

a)

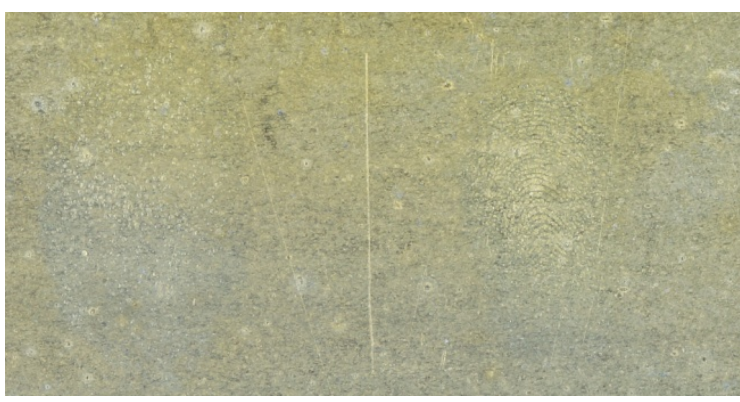

b)

Figure 16. Fingermarks on bronze after exposure to $600^{\circ} \mathrm{C}$ for a) 5 minutes, and b) 15 minutes, followed by treatment with $S_{2} N_{2}$

After 5 minutes, marks are clearly seen due to differences between deposition of the $(\mathrm{SN}) \times$ material on fingermark ridges and on the background. After 15 minutes, the oxidation of the surface has begun and although there is an indication of ridge detail for one of the marks this has been developed by the action of heat. There are signs of pale blue/grey deposits on some regions of the surface, but these are no longer clearly distinguishing the fingermark.

The appearance of marks developed using $\mathrm{S}_{2} \mathrm{~N}_{2}$ on stainless steel is different, Figure 17.
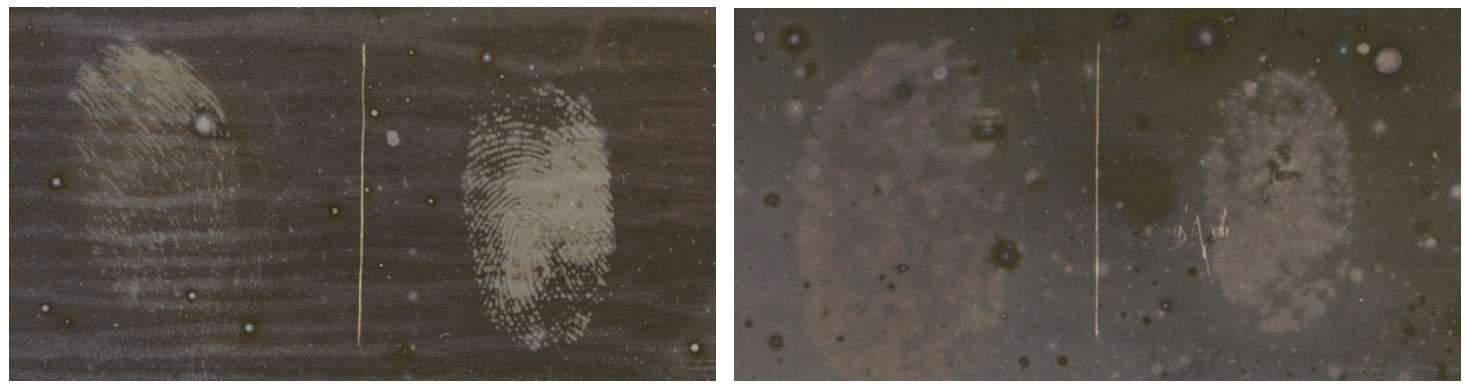

a)

b)

Figure 17. Fingermarks on stainless steel after exposure to $600^{\circ} \mathrm{C}$ for a) 5 minutes, and b) 15 minutes, followed by treatment with $\mathrm{S}_{2} \mathrm{~N}_{2}$ 
For the 5-minute exposure time, there is preferential deposition of material on the stainless steel which reveals the fingermark as paler ridges against a dark background. Although the same mode of development is observed for 15 minutes exposure, the fingermark ridges appear to have diffused across the surface, possibly associated with melting and flow of some of the constituents at the high temperatures. Wightman and O'Connor [12] also observed a colour change of a stainless steel surface to yellow-brown after exposure to equivalent conditions of $>5$ minutes at $600^{\circ} \mathrm{C}$ and attributed this to formation of an interference film. Although this surface had become slightly more yellow after initial exposure in this experiment, significant darkening to the brown colour observed in Figure 17 only occurred after additional exposure to $\mathrm{S}_{2} \mathrm{~N}_{2}$.

The diffusion of fingermarks is also observed for marks developed using superglue fuming on copper-based alloys, Figure 18.

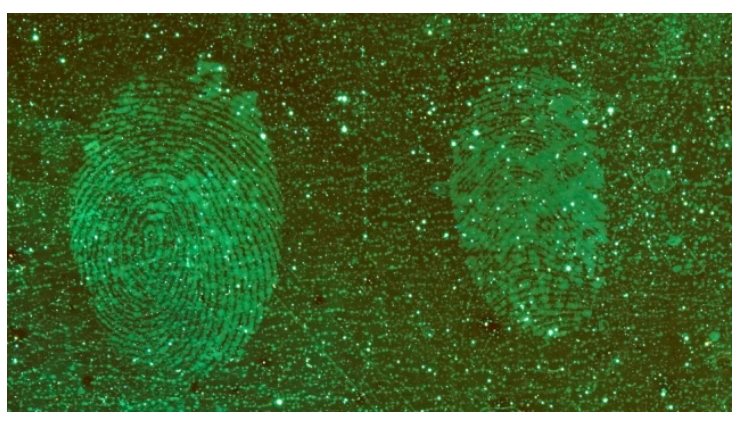

a)

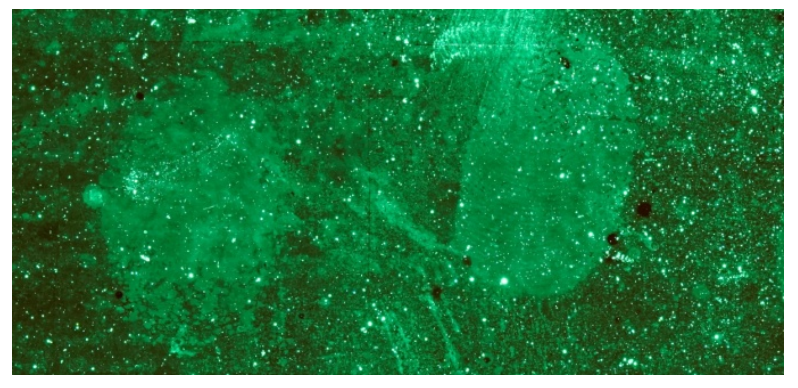

b)

Figure 18. Fingermarks on bronze after exposure to $600^{\circ} \mathrm{C}$ for a) 5 minutes, b) 15 minutes

After 5 minutes exposure fingermarks are still enhanced, but are very faint, and the ridge detail in one of the fingermarks is beginning to become diffuse. After 15 minutes, significant diffusion has occurred and only the outline of the fingermark can still be determined.

On stainless steel, diffusion of the marks is more rapid, with only featureless marks being observed after 5 minutes, Figure 19. After 15 minutes exposure there is no evidence of any fingermarks but after 1 hour 'negative marks' are detected, with a 'halo' of material (possible diffused fingermark constituents) being stained by BY40 surrounding dark ridges. After 4 hours exposure no marks are developed. This change in behaviour may be representative of a progressive interaction between fingermark constituents and the metal surface at elevated temperature. 


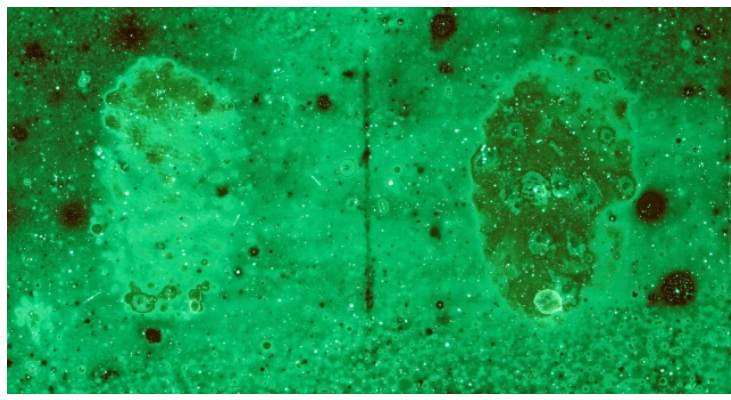

a)

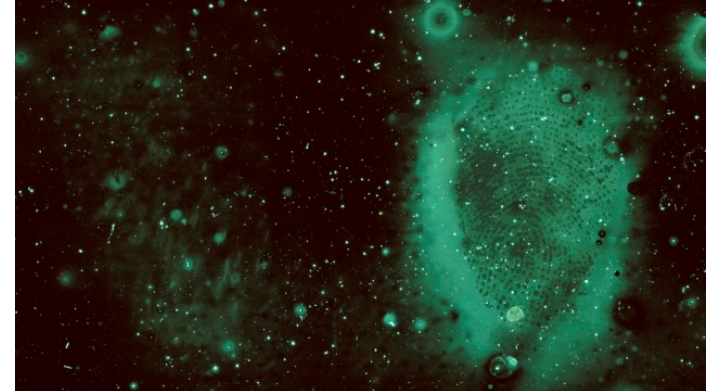

b)

Figure 19. Fingermarks on stainless steel after exposure to $600^{\circ} \mathrm{C}$ for a) 5 minutes, and b) 1 hour, followed by treatment with superglue fuming and BY40

Microscopy:

The SEM analysis of the samples showed differences in the way the $(\mathrm{SN}) \times$ polymer had formed on the surface, and this could be related to the appearance of the developed marks. The microstructures observed for each of the three metal surfaces are illustrated in Figures $20-22$.
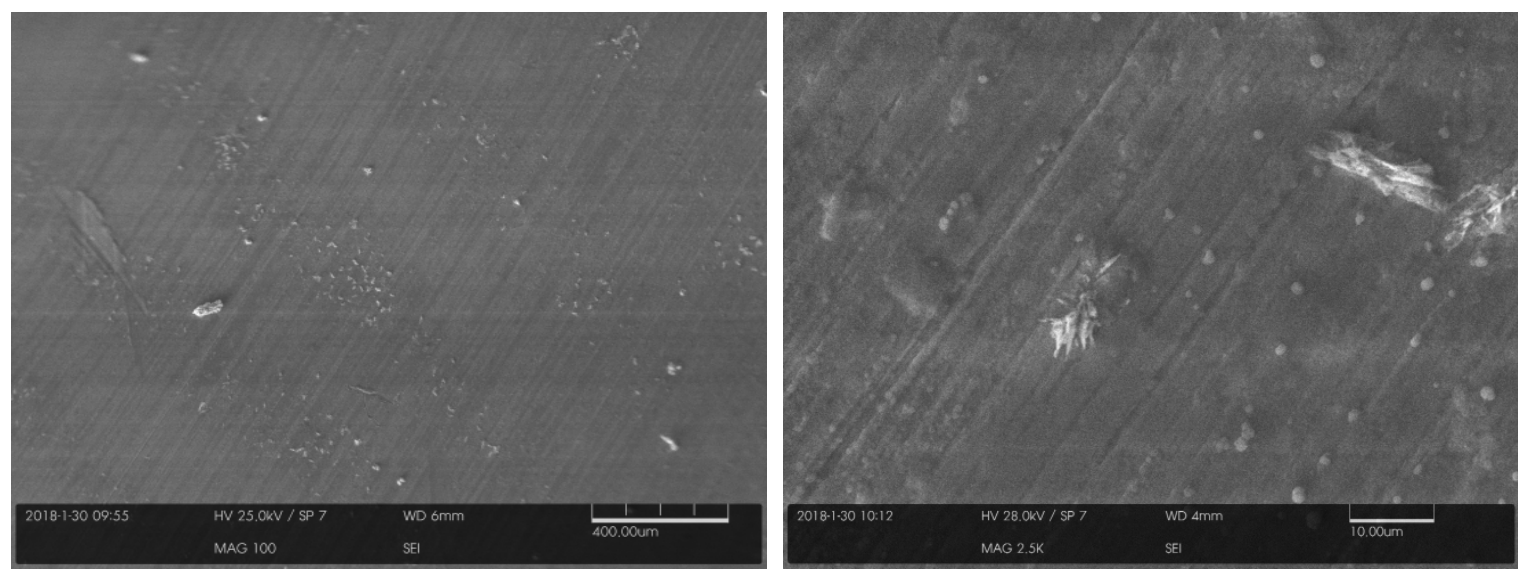

a)

b)

Figure 20. Microstructure of a fingermark developed using $\mathrm{S}_{2} \mathrm{~N}_{2}$ on a brass surface, a) $\times 100$, and b) $\times 2500$ 


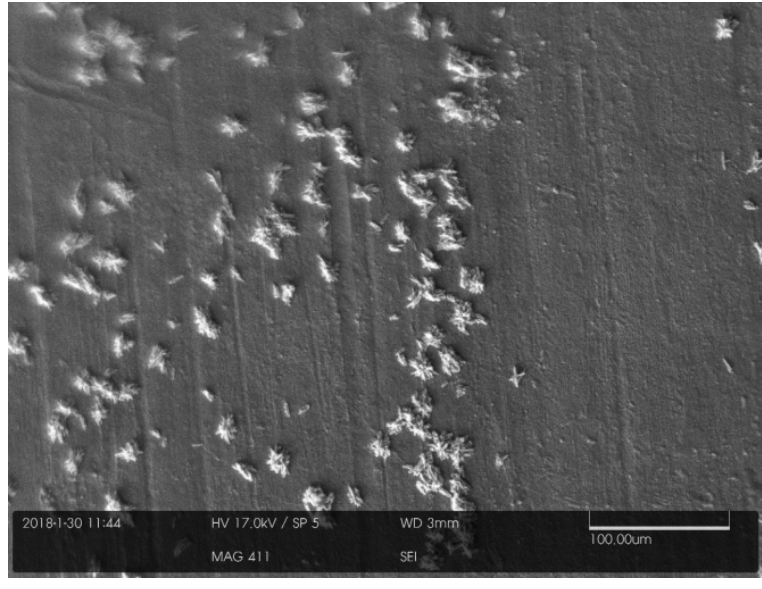

a)

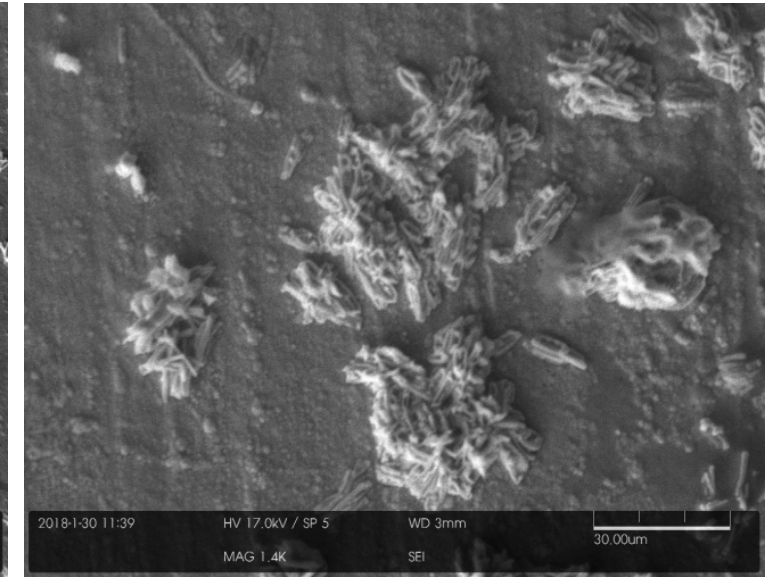

b)

Figure 21. Microstructure of a fingermark developed using $S_{2} N_{2}$ on a copper surface, a) $x 411$, and b) $x 1400$

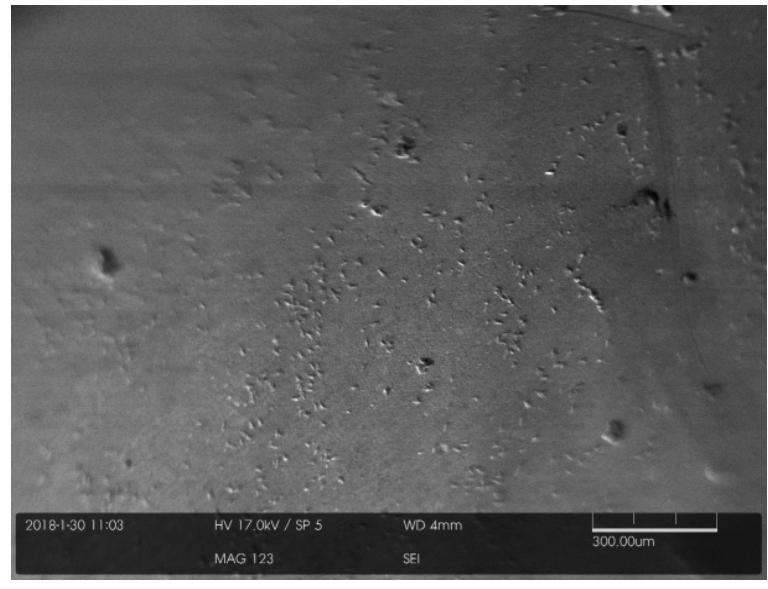

a)

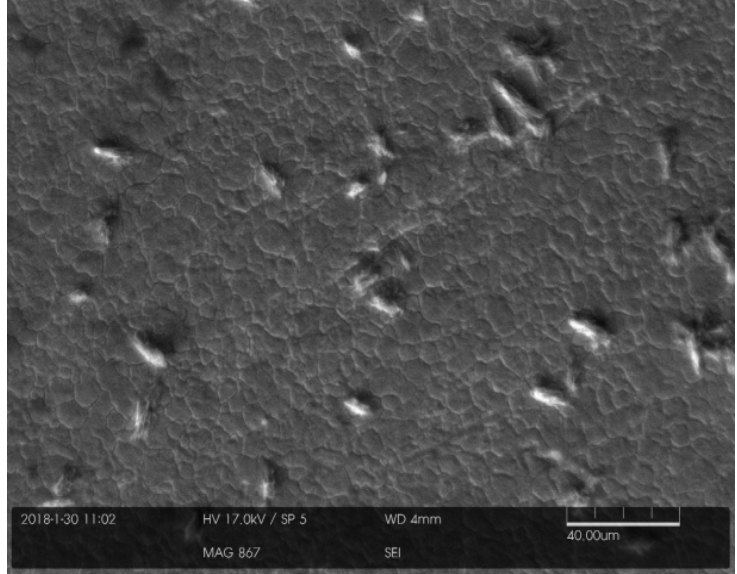

b)

Figure 22. Microstructure of a fingermark developed using $S_{2} N_{2}$ on a stainless steel surface a) $x 123$, and b) $x 867$

On the brass surface, Figure 20 , the low magnification image reveals fingermark ridges as regions where a higher density of larger structures has been deposited. At higher magnifications it appears that there is a general deposition of a surface layer with a spherical, pebble-like features, and the structure of the larger elongated features can be better seen.

On copper, Figure 21, the difference between the ridges and the background is more significant. Although there is still the general deposition of a surface layer containing fine spherical features, the features that grow on the ridges are far greater in size and appear to be agglomerations of the elongated structures seen on the brass surface. 
On stainless steel, Figure 22, it is difficult to distinguish the ridges from the background. However, the deposition is different in that there is no general deposition of $(\mathrm{SN}) \times$ across the entire surface, the granular structure of the original surface being plainly visible. Instead, there is a sparser deposition of elongated structures, thought to be $(\mathrm{SN})_{x}$ and responsible for the blueish tinge imparted to the stainless steel surface after treatment.

It has not yet been possible to identify what may be initiating the selective formation of the different structures that allow the fingermark ridges to be distinguished from the background on the brass and copper surfaces.

Overall, fingermarks were detected to varying degrees using all visualisation processes on surfaces where deliberate attempts had been made to wash them away. Possible explanations as to why each of the processes continue to develop marks are discussed below.

Cyanoacrylate fuming is a polymerisation process, and several fingermark constituents (e.g. lactic acid, alanine, weak bases such as water) can initiate polymerisation $[45,46]$. The salts present can reabsorb moisture from high humidity environments, providing water as a weak base that can initiate the process. It has been proposed that salts also contribute to corrosion of the surface in copper-based alloys. If the salts are removed by a washing action the surface may still have some surface oxides or hydroxides present along the fingermark ridges, which may provide an alternative source of initiation for cyanoacrylate polymerisation. SEM/EPMA $[44,47]$ and ToF-SIMS [48] on similar surfaces both indicate that oxygen content is higher in the regions of the ridges, which could support this theory.

Gun blueing is a masking process, where fingermark deposits form a protective barrier over the surface and prevent selenium interacting with the copper (and zinc) present to form selenium compounds [3]. It is expected to be more effective when marks are sebaceous in nature [23]. It is possible that the oxygen-rich regions present where fingermarks have initiated corrosion are providing a masking function after fingermark constituents themselves have been removed, albeit less effectively than sebaceous sweat.

Vacuum metal deposition discriminates fingermarks from the metal background because of differences in nucleation and growth rate of metal clusters on the surface [3]. This may be affected by surface energy, surface topography and the chemistry of species on the surface. VMD is sensitive enough to detect monolayers of fats on surfaces and this may explain why it performs poorly after the acetone wash. Acetone will readily dissolve the fat layer to leave a clean, more uniform surface. VMD therefore either gave no development at all on the acetone washed regions, or a uniform, featureless zinc coating. VMD may still develop fingermarks after water washing because the surface has been locally modified by interaction with the fingermark and still can produce differences in growth rate. Similar effects have been 
observed for development of marks originally deposited in blood on ceramic tiles and then exposed to high temperatures that burn the blood constituents away [49].

It has not been conclusively established how powder suspension develops fingermarks but it has been proposed that an electrical interaction contributes to particle deposition. It is therefore possible that residual surface charges associated with localised corrosion may assist with particle adhesion, but this would not explain the results obtained on stainless steel where corrosion is unlikely to occur.

The mechanism of fingermark development by $\mathrm{S}_{2} \mathrm{~N}_{2}$ has not yet been explored in detail but it is possible that both fingermark deposits and localised corrosion caused by fingermarks on the surface can act as preferential sites for $(\mathrm{SN})_{x}$ deposition. This should be the subject of future research activity.

Not all of the mechanisms described above are equally effective and/or sensitive to small traces of chemicals or corrosion on the surface, so some processes are more effective than others on washed surfaces. Results indicate that the longer the time the fingermark is left on the surface, the more likely that some record of the fingermark will be developed after washing. This supports the theory that corrosion signatures can be important on metal surfaces and the longer that corrosion is allowed to occur the greater the likelihood of developing the fingermark.

\section{Conclusions}

$\mathrm{S}_{2} \mathrm{~N}_{2}$ has been found to be an effective process for the visualisation of fingermarks on the range of metal surfaces studied. Of the processes investigated in this comparison, $\mathrm{S}_{2} \mathrm{~N}_{2}$ was the most consistent in visualising marks across the range of exposure conditions investigated.

Notable features of the $\mathrm{S}_{2} \mathrm{~N}_{2}$ process include:

- Ability to develop an identifiable fingermark on brass to at least the $36^{\text {th }}$ mark in a depletion series (i.e. high sensitivity)

- Ability to develop high quality fingermarks from a wide range of donors

- Ability to develop fingermarks up to 3 months old across the range of metals tested

- Ability to develop fingermarks on surfaces exposed to adverse conditions including water/detergent washing, acetone washing and exposure to extremely high temperatures

- There is potential to increase the number of high quality fingermarks visualised by the use of alternative lighting methods such as co-axial illumination

All of the other processes included in the study were also capable of visualising fingermarks on surfaces exposed to adverse conditions, and this was more common than anticipated at the beginning of the study. Observations made include: 
- The effectiveness of superglue fuming drops off more quickly with age of the mark than other processes

- Many of the marks developed using superglue fuming followed by dyeing with BY40 were not visible by eye, either using white light or fluorescence examination. The fact that they are detected by the imaging system implies that superglue may actually develop more marks than are currently being marked up

- Vacuum metal deposition appears to be most detrimentally affected by acetone washing

The results from this initial study indicate that $\mathrm{S}_{2} \mathrm{~N}_{2}$ may offer operational benefits over existing processes in several scenarios where metal surfaces are encountered. However, it will be necessary to revisit some of these experiments to demonstrate that the results obtained in this study using developmental equipment and processing protocols can be replicated using the commercially available processing chambers now available (RECOVER ${ }^{\circledR}$ - Foster + Freeman, Evesham, UK). Further work to build validation libraries of experimental data for the $\mathrm{S}_{2} \mathrm{~N}_{2}$ process should also extend these studies to substrates representative of casework, such as cartridge casings and knives, and to metal surfaces that have been subjected to weathering prior to deposition of fingermarks.

\section{Acknowledgements}

The authors would like to acknowledge the contribution of Andrew Gibson (formerly of CAST) to previous stages of the evaluation of the $\mathrm{S}_{2} \mathrm{~N}_{2}$ process, Steve Gibb of the CAST engineering workshops for his work in designing and building several pieces of the equipment used in this study, and Will Cheung of London South Bank University for carrying out the scanning electron microscopy.

This research did not receive any specific grant from funding agencies in the public, commercial, or not-for-profit sectors.

\section{References}

1. Quinche, N. and Margot, P. 'Coulier, Paul-Jean (1824-1890): a precursor in the history of fingermark detection and their potential use for identifying their source (1863)'. J. Forensic Ident. vol 60, (2010), p129-134

2. Ramotowski, R. (ed.) 'Lee and Gaensslen's Advances in Fingerprint Technology, Third Edition' CRC Press, 2012

3. Bleay, S. M., Croxton, R. S. and de Puit, M. 'Fingerprint Development Techniques', Wiley, 2018 
4. Bandey, H. L. (ed.) 'Fingermark Visualisation Manual' Home Office, 2014

5. Downham, R.P., Mehmet, S. and Sears, V.G. 'Pseudo-Operational Investigation Into the Development of Latent Fingerprints on Flexible Plastic Packaging Films', J. Forensic Ident., vol. 62 (6), (2012), p 661-682

6. Jones, N., Kelly, M., Stoilovic, M., Lennard, C., and Roux, C. 'The development of latent fingerprints on polymer banknotes,' J. Forensic Ident., vol. 53, (2003), p50-77

7. Wilkinson, D., Lam, R., Tse, T., Pynn, B. 'Recommended protocols for fingerprint detection on canadian polymer banknotes - part I: chemical development'. J. Forensic Ident., vol 64, (2014), p375-401.

8. Downham, R. P., Brewer, E. R., King, R. S. P., Luscombe, A. M. and Sears, V. G. 'Fingermark visualisation on uncirculated $£ 5$ (Bank of England) polymer notes: Initial process comparison studies', Forensic Sci. Int., vol. 275, (2017), p30-43

9. Downham, R.P., Kelly, S. and Sears, V. G., 'Feasibility studies for fingermark visualization on leather and artificial leather', J. Forensic Ident., vol. 65(2), (2015) p138-159

10. Fraser. J., Sturrock, K., Deacon, P., Bleay, S. and Bremner, D. H. 'Visualisation of fingermarks and grab impressions on fabrics. Part 1: gold/zinc vacuum metal deposition', Forensic Sci. Int., vol. 208(1-3), (2011), p74-8.

11. Fairley, C., Bleay, S. M., Sears, V. G., NicDaeid, N., 'A comparison of multi-metal deposition processes utilising gold nanoparticles and an evaluation of their application to 'low yield' surfaces for finger mark development', Forensic Sci Int. vol. 217(1-3), (2012), p5-18

12. Wightman, G, O'Connor, D. 'The thermal visualisation of latent fingermarks on metallic surfaces'. Forens Sci Int. vol 204(1-3), (2011), p88-96

13. Bond J W, 'Visualisation of latent fingerprint corrosion of metallic surfaces', J Forens Sci, vol 53 (4), (2008), p812-822

14. Bond J W, 'The Thermodynamics of Latent Fingerprint Corrosion of Metal Elements and Alloys', J Forens Sci, vol 53(6), (2008), p1344-1352

15. House of Commons Transport Committee, 'Cable theft on the railway', Fourteenth report of Session 2012, HC 1609, The Stationery Office Ltd, 26 January 2012

https://publications.parliament.uk/pa/cm201012/cmselect/cmtran/1609/1609.pdf (accessed 20 November 2018)

16. Metropolitan Police Service FY 2016/17 Crime Statistics https://public.tableau.com/profile/metropolitan.police.service\#!/vizhome/MPSFY2016

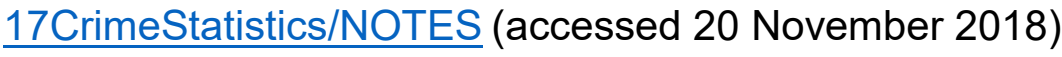


17. Given B W, 'Latent Fingerprints on Cartridges and Expended Cartridge Casings', J Forens Sci, vol 21(3), (1976), p587-594

18. Belcher G L, 'Methods of Casting and Latent Print Recovery', Fingerprint Identification Magazine, vol 59(1), (1977), p14-5

19. Belcher G L, 'Developing Latents on Copper-coated Casings', Fingerprint Whorld, vol 6(22), (1980), p39

20. Cantu A A, Leben D A, Ramotowski R, Kopera J, Simms J R, 'Use of Acidified Hydrogen Peroxide to Remove Excess Gun Blue from Gun Blue-Treated Cartridge Cases and to Develop Latent Prints on Untreated Cartridge Cases', J Forens Sci, vol 43(2), (1998), p294-8

21. Migron $Y$, Mandler $D$, 'Development of Latent Fingerprints on Unfired Cartridges by Palladium Deposition: A Surface Study', J Forens Sci, vol 42(6), (1997), p986-992

22. Smith K, Kauffman C, 'Enhancement of Latent Prints on Metal Surfaces', J Forens Ident, vol 51(1), (2001), p9-15

23. James, $R$ M, Altamimi, M J, 'The enhancement of friction ridge detail on brass ammunition casings using cold patination fluid', Forens Sci Int, vol 257, (2015), p385-392

24. Bentsen R K, Brown J K, Dinsmore A, Harvey K K, Kee T G, 'Post Firing Visualisation of Fingerprints on Spent Cartridge Cases', Sci Justice, vol 36, (1996), p3-8

25. Saunders G C, Cantu A A, 'Evaluation of Several Techniques for Developing Latent Fingerprints on Unfired and Fired Cartridge Cases', Proceedings of the International Symposium on Fingerprint Detection and Identification, June 26-30, 1995, Ne'urim, Israel, p155-160

26. Dominick A J, Laing $K$, 'A comparison of six fingerprint enhancement techniques for the recovery of latent fingerprints from unfired cartridge cases'. J. Forens Ident. vol 61(2), (2011), p155-165

27. Girelli C M A, Lobo B J M, Cunha A G, Freitas J C C, Emmerich F G, 'Comparison of practical techniques to develop latent fingermarks on fired and unfired cartridge cases', Forens Sci Int, vol 250, (2015), p17-26

28. Wiesener S, Springer E, Argaman U, 'A Closer Look at the Effects of the Shooting Process on Fingerprint Development on Fired Cartridge Cases', Proceedings of the International Symposium on Fingerprint Detection and Identification, June 26-30, 1995, Ne'urim, Israel, p161-178

29. Williams G, McMurray H N, Worsley D A, 'Latent Fingerprint Detection Using a Scanning Kelvin Microprobe', J Forens Sci, vol 46(5), (2001), p1085-1092 
30. Williams G, McMurray N, 'Latent Fingerprint Visualisation Using a Scanning Kelvin Probe', Forens Sci Int, vol 167, (2007), p102-9

31. Bond J W, Heidel C, 'Visualisation of latent fingerprint corrosion on a discharged brass shell casing', J Forens Sci, vol 54(4), (2009), p892-894

32. King, R. S. P., Kelly, P. F., Dann, S. E. and Mortimer, R. J., 'Rapid polymerisation of $\mathrm{S}_{2} \mathrm{~N}_{2}$ within Na-ZSM-5 channels', Chem. Commun. (Camb.), (2007), p4812-4814.

33. Kelly, P. F., King, R. S. and Mortimer, R. J. 'Fingerprint and inkjet-trace imaging using disulfur dinitride', Chem Commun (Camb). (2008), p6111-3

34. Kelly, P. F., King, R. S. P., Shah, B. and Mortimer, R. J. 'The use of sulfur nitrides as fingerprint developers', Proc. SPIE 7486, Optics and Photonics for Counterterrorism and Crime Fighting V, 748602 (17 September 2009); doi: $10.1117 / 12.833980$

35. Bleay S M, Kelly P F, King R S P, 'Polymerisation of $S_{2} N_{2}$ to $(S N) \times$ as a tool for the rapid imaging of fingerprints removed from metal surfaces', J. Mater. Chem., vol 20, (2010), p10100-10102

36. Beresford A L, Hillman A R. 'Electrochromic Enhancement of Latent Fingerprints on Stainless Steel Surfaces'. Anal Chem, vol 82, (2010), p483-486

37. Beresford A L, Brown R M, Hillman A R. 'Comparative Study of Electrochromic Enhancement of Latent Fingerprints with Existing Development Techniques'. J Forens Sci, vol 57, (2011), p93-102

38. Dominick, A. J., Nic Daéid, N., and Bleay, S. M. 'The recoverability of fingerprints on nonporous surfaces exposed to elevated temperatures'. J. Forensic Ident., vol 61(5), (2011), p520-536

39. Pitera M, Sears V, Bleay S, Park S 'An investigation of the influence of surface condition on fingermark visualisation on metal surfaces' submitted for publication in Science and Justice

40. Sears, V. G., Bleay, S. M., Bandey, H. L., and Bowman, V. J. 'A methodology for finger mark research', Science and Justice, vol 52(3), (2012), p145-160

41. International Fingerprint Research Group (IFRG), 'Guidelines for the Assessment of Fingermark Detection Techniques' J. Forensic Ident., vol. 64 (2), (2014), p174-200

42. McLaren, C., Lennard, C. and Stoilovic, M. (2010), 'Methylamine pretreatment of dry latent fingermarks on polyethylene for enhanced detection by cyanoacrylate fuming', J. Forensic Ident., vol 60(2), p199 - 22243.

43. Cohen Y, Rozen E, Azoury M, Attias D, Gavrielli B, Levin Elad M, (2012), 'Survivability of Latent Fingerprints Part I: Adhesion of Latent Fingerprints to Smooth Surfaces', J. Forens Ident., vol 62(1), p47-53 
44. Wightman, G, Emery, F, Austin, C, Andersson, L, Harcus, L, Arju, G and Steven, $C$, (2015), 'The interaction of fingermark deposits on metal surfaces and potential ways for visualisation', Forens. Sci. Int. vol 249, p241-254

45. Lewis, L. A., Smithwick III, R. W., Devault, G. L., Bolinger, B. and Lewis Sr, S. A. (2001) 'Processes Involved in the Development of Latent Fingerprints Using the Cyanoacrylate Fuming Method', J. Forens. Sci., vol. 46 (2), pp 241-246.

46. Wargacki, S. P., Lewis, L. A. and Dadmun. M. D. (2007) 'Understanding the Chemistry of the Development of Latent Fingerprints by Superglue Fuming', J. Forens. Sci., vol. 52 (5), pp 1057-1062.

47. Challinger, S E, Baikie, I D, Flannigan G, Halls, S, Laing, K, Daly, L and nic Daeid, N. (2018), 'Comparison of scanning Kelvin probe with SEM/EPMA techniques for fingermark recovery from metallic surfaces', Forens. Sci. Int., vol 291, p44-52

48. Thandauthapani, T D, Reeve, A J, Long, A S, Turner, I J and Sharp, J S, (2018) 'Exposing latent fingermarks on problematic metal surfaces using time of flight secondary ion mass spectrometry', Science \& Justice vol 58, p405-414

49. Moore, J.E., Bleay, S.M., Deans, J.J. and Nic Daeid N. (2008) 'Recovery of fingerprints from arson scenes Part 2 - Fingerprints in Blood', J Forens Ident, 58(1), 83-108 